\title{
Chemical Treatment of Banana Blossom Peels Adsorbent as New Approach for Manganese Removal: Isotherm and Kinetic Studies
}

\section{Nurul Nadia Rudi}

Universiti Tun Hussein Onn Malaysia

Najeeha Mohd Apandi

Universiti Tun Hussein Onn Malaysia

Mimi Suliza ( $\square$ msuliza@uthm.edu.my)

Universiti Tun Hussein Onn Malaysia https://orcid.org/0000-0003-0609-8486

Suhair Omar

Universiti Tun Hussein Onn Malaysia

Norshuhaila Mohamed Sunar

Universiti Tun Hussein Onn Malaysia

Lee Te Chuan

Universiti Tun Hussein Onn Malaysia

Ramathasan Nagarajah

Universiti Tun Hussein Onn Malaysia

\section{Research Article}

Keywords: Banana blossom peels, Manganese, Adsorption isotherm, Kinetic study, Desorption

Posted Date: February 23rd, 2022

DOI: https://doi.org/10.21203/rs.3.rs-1319392/v1

License: (9) (i) This work is licensed under a Creative Commons Attribution 4.0 International License.

Read Full License 


\section{Chemical Treatment of Banana Blossom Peels Adsorbent as New}

\section{Approach for Manganese Removal: Isotherm and Kinetic Studies}

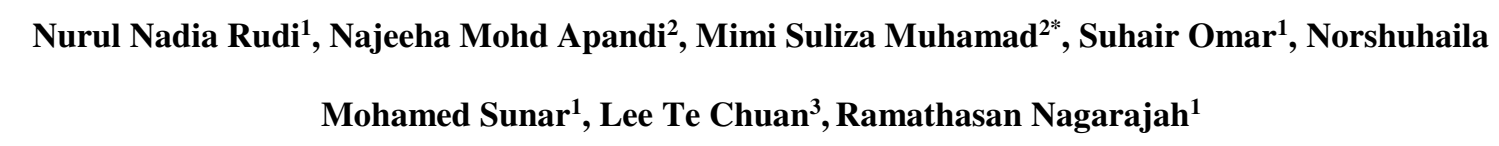

${ }^{1}$ Department of Civil Engineering Technology, Faculty of Civil Engineering Technology,

Universiti Tun Hussein Onn Malaysia, Pagoh Education Hub, 84600 Pagoh, Muar, Johor, Malaysia

${ }^{2}$ Sustainable Engineering Technology Research Centre (SETechRC), Faculty of Engineering Technology,

Universiti Tun Hussein Onn Malaysia, Pagoh Education Hub, 84600 Pagoh, Muar, Johor, Malaysia

${ }^{3}$ Department of Production and Operation Management, Faculty of Technology Management and Business, Universiti Tun Hussein Onn Malaysia, 86400 Parit Raja, Batu Pahat, Johor, Malaysia

*Corresponding author:

Mimi Suliza Muhamad

E-mail: $\underline{\text { msuliza@uthm.edu.my }}$ 
The current study determined the potential of chemical modified banana blossom peels (BBP) as an adsorbent for the removal of manganese (Mn) from water. The BBP adsorbent was characterized using Field Emission Scanning Electron Microscopy (FESEM), Fourier Transform Infrared Spectroscopy (FTIR), X-Ray Diffraction (XRD) and Brunauer-Emmet Teller (BET). The effects of the solution $\mathrm{pH}$, adsorbent dosage, initial manganese concentration and contact time towards the adsorption process were evaluated in batch adsorption studies. FESEM analysis displayed a deeper dents and rough internal surface that cater for deposition of Mn, while EDX analysis detected the presence of $\mathrm{C}, \mathrm{O}$, and $\mathrm{Na}$ elements (before adsorption); $\mathrm{C}, \mathrm{O}$ and $\mathrm{Mn}$ (after adsorption). FTIR analysis revealed presence hydroxyl, carboxylic and amino groups which are responsible for the adsorption process. Moreover, $\mathrm{XRD}$ analysis showed that the structure of the BBP adsorbent is amorphous. The BET surface area of BBP adsorbent was $2.12 \mathrm{~m}^{2} / \mathrm{g}$ with the total pore volume of $0.0139 \mathrm{~cm}^{3} / \mathrm{g}$ and average pore diameter of $64.35 \mathrm{~nm}$. The BBP adsorbent showed promising results of $98 \% \mathrm{Mn}$ removal at optimum condition of $\mathrm{pH} \mathrm{7,} 0.5 \mathrm{~g}$ (adsorbent dosage), $10 \mathrm{mg} / \mathrm{L}$ of $\mathrm{Mn}$ initial concentration in $150 \mathrm{~min}$ contact time. Adsorption isotherm data were fitted with linear Langmuir and linear Freundlich model best fit with $\mathrm{R}^{2}>0.98$, while the adsorption process take place as a function of chemisorption process as determined using linear pseudo-second order kinetics. The maximum desorption rate of $\mathrm{Mn}$ was achieved at $92 \%$ in the first cycle with recovery rate of $94.18 \% \mathrm{Mn}$ removal within 30 min using $0.1 \mathrm{M} \mathrm{HCl}$. These findings confirmed the potential BBP as a natural adsorbent for Mn removal as an effective treatment option for enhancing wastewater quality. 
All procedures performed in the present study involving human participants were in accordance with the ethical standards of the institutional and/or national research committee.

\section{Consent for publication}

$45 \quad$ Not applicable

\section{$46 \quad$ Availability of data and materials}

47 The authors confirm that the data supporting the findings of this study are available within the article. The lead author* affirms that this manuscript is an honest, accurate, and transparent account of the study being reported; that no important aspects of the study have been committed; and that any discrepancies from the study as planned and have been explained.

\section{Competing Interests}

The authors declare that they have no competing interests.

\section{Funding}

54 This study was funded by the Ministry of Higher Education (MOHE), Malaysia under the Fundamental Research Grant Scheme grant (K219) (FRGS/1/2019/TK10/UTHM/03/3).

\section{Authors contributions}

57 All authors contributed to the study conception and design. Conceptualization: Mimi Suliza Muhamad; 58 Methodology: Mimi Suliza Muhamad; Norshuhaila Mohamed Sunar; Material preparation, data collection, and analysis: Nurul Nadia Rudi; Najeeha Mohd Apandi; Ramathasan Nagarajah, Writing - original draft preparation: Nurul Nadia Rudi; Review and editing: Najeeha Mohd Apandi; Mimi Suliza Muhamad, Ramathasan Nagarajah; Funding acquisition: Mimi Suliza Muhamad, Resources: Suhair Omar; Lee Te Chuan, Supervision: Mimi Suliza Muhamad; The first draft of the manuscript was written by Nurul Nadia Rudi and all authors commented on previous versions of the manuscript. All authors read and approved the final manuscript. 


\section{Acknowledgement}

65 The authors thank the parties involved in this project, especially Universiti Tun Hussein Onn Malaysia, for 66 providing the research facilities and equipment. The authors wish to thank the Ministry of Higher Education 67 Malaysia for the Fundamental Research Grant Scheme grant (K219) (FRGS/1/2019/TK10/UTHM/03/3).

\section{Conflict of Interest Statement}

69 We declare that this manuscript is original, has not been published before and is not currently being considered 70 for publication elsewhere. We have no conflicts of interest to disclose with this publication. We have no known 71 competing financial interests or personal relationships that could have appeared to influence the work reported in 72 this paper. 
74

The rapid industrial development has increased water sources pollution (Ahmed et al. 2014). Disposal of contaminants that include toxic sludge, solvents, and heavy metals from industrial activities into water bodies had been reported to be 300-400 million tonnes annually (Singh et al. 2018). The number of polluted water sources in Malaysia increases over time due to the uncontrollable waste disposal and effluent discharge from industry (Marsidi et al. 2018). The waterworks company had alarmed the presence of heavy metals detected in river due to discharged from industrial effluents (Zou et al. 2016). In steel production, manganese (Mn) had been widely used and discharged in the industrial effluents. Mn is a trace metal that is found mainly as oxides, carbonates, and silicates in many different minerals, with pyrolusite (manganese dioxide) as the most common naturally-occurring form (Milatovic and Gupta, 2018). Mn can be found abundantly in the earth's crust and water sources, which exist in a broad range of oxidation states and species in the water (Tobiason et al., 2016)

Upon oxidation, Mn becomes insoluble in water and change the colour of the water into brown-red colour, making the water aesthetically unpleasant and unfit for drinking (Marsidi et al. 2018; Bouchard et al. 2018; Ali et al. 2017; Rumsby et al. 2018). Studies have shown consumption of high Mn concentration in drinking water led to adverse health effects related to neurological disorders, intellectual, and cognitive development (Rumsby et al. 2018; Gerke et al. 2016). Accumulation of excessive Mn ions in specific brain areas can cause neurotoxicity and degenerative brain disorder (Idrees et al. 2018; Milatovic and Gupta, 2018). Exposure of 240$350 \mu \mathrm{g} / \mathrm{L} \mathrm{Mn}$ ions concentration toward children displayed symptoms of reduced manual dexterity, speed, shortterm memory, and visual recognition (Mthombeni et al. 2016).

Various treatment technologies have been used to treat water containing manganese including ion exchange, oxidation, chemical precipitation, electrochemical treatment, ozone, membrane filtration, and ultraviolet irradiation (Baysal et al. 2013; Carolin et al. 2017; Al-Jubouri and Holmes, 2013; Du et al. 2019; Alvarez-Bastida et al. 2018; Jeirani et al. 2015; Fatemeh et al. 2018; Ihsanullah et al. 2016; Ahmadi et al. 2019). Most of the technologies are able to remove $\mathrm{Mn}$ in water, however there are some problems arise such as complex process, space requirements, treatment capacity, sludge disposal, high operational and maintenance cost (Marsidi et al. 2018; Ali 2017; Jawed and Pandey 2019). Among the treatment technologies, adsorption process has been known to be effective in removing contaminants with minimal problem. Agricultural waste adsorbent particularly has gaining attention among researchers in treating water containing Mn ions owing to its efficiency, availability, environmental friendly, and easy to produce (Jawed and Pandey. 2019). Agricultural waste are found abundantly 
in Malaysia and can be utilize to produce low-cost adsorbents. Banana plant particularly is widely planted and used for many purposes. About $16 \%$ of the total fruit production encompass of banana making it the second largest fruit produced worldwide with the highest of 32\% produced fruit in Malaysia (Pathak et al. 2017).

Currently, the study on banana blossom as adsorbent for the removal of contaminant is limited. Gopakumar et al. (2018) studied on banana blossom peels adsorbent by simply washing and drying the peels under sunlight. The banana blossom peels (BBP) adsorbent is able to remove $79.72 \%$ turbidity, $88.24 \%$ total solids, and $61.01 \%$ chloride in lake water sample as well as reducing the alkalinity of the water to neutral $\mathrm{pH}(8.4$ to 6.75$)$. Herawati et al. (2018) used BBP adsorbent to treat dyes that able to removed Congo Red dye (1.78\%), Remazol Yellow dye (4.29\%), Methylene Blue dye (0.43\%), and Remazol Black dye $(0.56 \%)$. Yet, chemical treatment of $\mathrm{BBP}$ as an adsorbent for Mn removal has not been investigated before.

According to our knowledge, no study was performed on the isotherm and kinetic studies towards the reusability and application of the chemical modified BBP adsorbent for Mn removal. Therefore, the present study attempts to synthesize banana blossom peels (BBP) via chemical treatment method. The adsorption behaviour of the $\mathrm{Mn}$ onto the BBP adsorbent was investigated in terms of different factors that influence the process including $\mathrm{pH}$, adsorbent dosage, initial manganese concentration and contact time. The adsorption mechanism analysis was elucidated by isotherm and kinetic studies to determine the mechanism of the adsorption process.

\section{MATERIALS AND METHODS}

\subsection{Preparation of Banana Blossom Peels Adsorbent}

Banana blossom peels (BBP) were obtained from the banana planters located in Pagoh Jaya, Muar, Johor, Malaysia. BBP was cleansed and washed thoroughly to remove impurities on the surface; then the BBP was then cut into small pieces' oven dried at $60^{\circ} \mathrm{C} \pm 1^{\circ} \mathrm{C}$ for $12 \mathrm{hrs}$. The BBP were grounded and sieved into powder with standard mesh ring of 150-212 $\mu \mathrm{m}$. The obtained BBP powder was immersed in $20 \mathrm{ml}$ of $1 \mathrm{M} \mathrm{HCl}$ and sodium hydroxide $(\mathrm{NaOH})$. The BBP powder with chemical activation solutions were stirred in an orbital shaker at 150 rpm for 30 min. The BBP was then rinsed with distilled water to eliminate any remaining chemical on the surface. The BBP powder is next dried in an oven at $60^{\circ} \mathrm{C} \pm 1{ }^{\circ} \mathrm{C}$ for $12 \mathrm{hrs}$ (Surovka and Pertile 2017) until it dry and sieve using standard 60 mesh sieve. The schematic representation of BBP adsorbent preparation is shown in Figure 1.

\subsection{Characterization of Banana Blossom Peels Powder}

Field emission scanning electron microscope (FESEM) and Energy Dipersive X-ray (EDX) were used to determine the surface morphology and elemental composition of BBP adsorbent. The functional groups in BBP 

conducted at resolution of $4 \mathrm{~cm}^{-1}$ and the reading was recorded at mid-infrared of region 4000 to $400 \mathrm{~cm}^{-1}$. X-ray Diffraction (XRD) pattern using Bruker D8 Advanced was utilized to determine the crystalline structure of the BBP pattern using Bruker D8 Advanced. X-rays of $1.5406 \AA$ wavelength was generated by $\mathrm{Cu} \mathrm{K} \alpha$ monochromatic radiation. The BBP adsorbent was compressed in a cassette sample holder and the data was collected from $2 \theta=$ $20^{\circ}-80^{\circ}$ with sampling pitch of $0.02^{\circ}$.

The surface area, total pore volume, and pore diameter were measured by a Brunauer-Emmett-Teller

141 (BET) method based on nitrogen adsorption-desorption at 77K (Thermo Scientific surface area and pore analyser).

142 Prior to analyses, the BBP adsorbent sample was outgassed at $60{ }^{\circ} \mathrm{C}$ for $24 \mathrm{hrs}$.

\subsection{Batch Adsorption Experiment}

Batch adsorption experiments were conducted in $250 \mathrm{~mL}$ conical flask shaken by using Stuart orbital shaker at $150 \mathrm{rpm}$ with different $\mathrm{pH}(4-9)$, adsorbent dosage (0.1-0.7 g/L), initial $\mathrm{Mn}^{2+}$ concentrations $(10-50 \mathrm{mg} / \mathrm{L})$ and contact time (60-180 minutes). A stock solution with Mn concentration of $100 \mathrm{mg} / \mathrm{L}$ was prepared by dissolving $0.308 \mathrm{~g}$ of manganese (II) sulphate in one $\mathrm{L}$ deionized water. The experimental solutions were further diluted to different concentrations of $10-50 \mathrm{mg} / \mathrm{L}$ in $1 \mathrm{~L}$ flasks. The Mn removal efficiency (\%) and adsorption capacity, $\mathrm{q}_{\mathrm{e}}(\mathrm{mg} / \mathrm{g})$ were determined as follows:

$$
\operatorname{Removal}(\%)=\frac{\left(C_{0}-C_{e}\right)}{C_{o}} \times 100
$$

152

$$
\mathrm{q}_{\mathrm{e}}=\frac{\mathrm{v}\left(\mathrm{C}_{\mathrm{o}}-\mathrm{C}_{\mathrm{e}}\right)}{\mathrm{w}}
$$

where:

$157 \quad \mathrm{C}_{\mathrm{o}}(\mathrm{mg} / \mathrm{l})$ : Initial Mn concentration

$158 \mathrm{C}_{\mathrm{e}}(\mathrm{mg} / \mathrm{l})$ : Equilibrium Mn concentration in solution

$159 \mathrm{qe}(\mathrm{mg} / \mathrm{g})$ : The amount of metal ions

160 V: The solution volume (L)

161 W: The mass of BBP adsorbent (g). 

concentration using inductively coupled plasma optical emission spectrometry (ICP-OES) (Perkin Elmer, Optima 8000). This technique was to measure the concentration of Mn before and after the adsorption batch experiments procedure.

\subsection{Adsorption Isotherms Studies}

The adsorption isotherms are important in order to demonstrate the behaviour, mechanism and the optimum fitting through metal ions concentration in the liquid state in the surface of adsorbents at a given concentration (Mahmoud et al, 2014). In this study, the adsorption isotherm was analyzed by Langmuir and Freundlich model to find out the relationship between the $\mathrm{Mn}^{2+}$ concentration adsorbed by $\mathrm{BBP}$ according to the linear and non-linear equations.

Linear:

$$
\frac{C_{e}}{q_{e}}=\frac{1}{q_{\max } b}+\frac{C_{e}}{q_{\max }}
$$

Non-Linear:

$$
q_{e}=\frac{q_{\max } \pm b C_{e}}{\left(1+b C_{e}\right)}
$$

where $\mathrm{C}_{\mathrm{e}}$ is the equilibrium concentration of solute and $\mathrm{q}_{\max }$ is monolayer capacity of the adsorbent al. 2014). adsorption. The Freundlich isotherm is presented by the following equation:

Linear:

$$
\log q_{e}=\log K_{F}+\frac{1}{n} \log C_{e}
$$

Non-linear:

$$
q_{e}=K_{f}+C_{e}{ }^{1 / n}
$$


Where Kf is the Freundlich constants denoting the adsorption capacity $(\mathrm{mg} / \mathrm{L})$, qe is the uptake of pollutant per unit weight of biosorption $(\mathrm{mg} / \mathrm{L})$, Ce is the equilibrium of concentration $(\mathrm{mg} / \mathrm{L})$, and $\mathrm{n}$ is the empirical constant indicating of adsorption intensity

192

193

\subsection{Adsorption kinetics studies}

The Mn removal data obtained from the experiment under optimal conditions were applied to linear and non-linear models of pseudo first and second order kinetics to generate the prediction adsorption data. The reaction rate and mechanism of adsorption process can be determined from kinetic study. The pseudo-first order assumes that the uptake rate of Mn ions with time is directly proportional to the number of unoccupied sites on the BBP adsorbent (Fathi et al. 2020). The pseudo-first order equation which represented the adsorption of a solute from a liquid solution is written as below:

\section{Linear:}

$$
\ln \left(\mathrm{q}_{\mathrm{e}}-\mathrm{q}_{\mathrm{t}}\right)=\ln \mathrm{q}_{\mathrm{e}}-\mathrm{K}_{1} \mathrm{t}
$$

Non-linear:

$$
\mathrm{q}_{\mathrm{t}}=\mathrm{q}_{\mathrm{e}}\left(1-{ }^{e-\mathrm{K} 1 \mathrm{t}}\right)
$$

Where $\mathrm{q}_{\mathrm{e}}$ is the adsorbed metal ion mass at equilibrium $(\mathrm{mg} / \mathrm{g}), \mathrm{q}_{\mathrm{t}}$ is the adsorbed metal ion mass at time $\mathrm{t}(\mathrm{mg} / \mathrm{g})$, $\mathrm{K}_{1}$ is the pseudo-first-order reaction rate constant ( $\left.1 / \mathrm{min}\right)$. Meanwhile, the pseudo-second order kinetic model assumes that chemical adsorption can be the rate limiting stage involving valence forces through sharing or exchange of electrons between adsorbent and adsorbate (Zhang et al. 2014). The pseudo-second order equation depends on the adsorption equilibrium capacity which is expressed as below:

Linear:

$$
\frac{\mathrm{t}}{q_{t}}=\frac{1}{K_{2} q_{e}^{2}}+\frac{t}{q_{e}}
$$

Non-linear:

$$
q_{t}=\frac{k^{2} q_{e}^{2} \mathrm{t}}{1+k^{2} \mathrm{q}_{\mathrm{e}} \mathrm{t}}
$$


where $\mathrm{K}_{2}$ is a constant that represents the pseudo-second order reaction rate equilibrium (g/mg min) (Fathi et al. 2020).

\subsection{Desorption experiment}

221

The reusability of the BBP adsorbent was assessed by desorption experiment. The manganese pre-sorbed BBP adsorbent samples $(0.5 \mathrm{~g})$ were contacted with $100 \mathrm{ml}$ of $0.5 \mathrm{M} \mathrm{HCL}$ in a conical flask and shaken at 150 rpm at room temperature. The sample was then collected at certain time interval and filter prior to be analysed for manganese concentration using ICP-OES.

\section{Results and discussion}

\subsection{Characterization of BBP Adsorbent \\ 3.1.1. Surface Morphology and EDX Analysis}

The surface morphology, microstructures and physical properties of BBP adsorbent was determined using FESEM before and after Mn adsorption are depicted in Figure 2 and 3, respectively. The surface of BBP adsorbent is crimped with deeper dents, rough internals surface and dense in nature (Figure 2). The morphology of BBP may facilitate the adsorption of Mn owing to high irregular surface that provide maximum surface area for the adsorption of manganese ions (Fathi et al. 2020; Zhang et al. 2014; Abdeen et al. 2014; Bediako et al. 2019). Figure 2 and 3 shows the presence of prominent carbon $(\mathrm{C})$, oxygen $(\mathrm{O})$, and sodium $(\mathrm{Na})$ elements from EDX analysis.

The BBP adsorbent's FESEM micrograph (Figure 3) reveals changes in shape indicating $\mathrm{Mn}^{2+}$ adsorption onto the BBP. The morphologies of FESEM in Figure 3 were observed to undergo changes after adsorption process where it has less crimped and rough surface compare to the pristine BBP adsorbent. The surfaces became loose porous might due to the vigorous shaking and interactions with the Mn solutions and water molecules creates micro-channels through Mn ions penetration to the internal binding sites (Bediako et al. 2019). Shiny particles were also observed over the surface of BBP after the adsorption takes place. Furthermore, the EDX spectra in Figure 3 detects an additional peak of Mn confirming the uptake of Mn ions onto the surface of BBP adsorbent.

\subsubsection{FTIR Analysis}

The functional groups detected in BBP adsorbent before and after manganese adsorption is shown in Figure 4 (a) and (b), respectively. Figure 4 (a) shows the broad transmission band at around $3288 \mathrm{~cm}^{-1}$ can be 
attributed to the overlapping of hydroxyl group $\mathrm{O}-\mathrm{H}$ (carboxylic acid), $\mathrm{C}-\mathrm{O}$ stretching and $\mathrm{N}-\mathrm{H}$ (amino groups) of macromolecular association (Mahmoud et al. 2014). The $-\mathrm{OH}$ or $-\mathrm{NH}$ stretch band was shifted to $3276 \mathrm{~cm}^{-1}$ which can be seen in Figure 4(b), implying that the adsorption involved - OH and C-O stretching of alcohol or NH deformation (Chen et al. 2015). BBP contains C-H stretching vibration around $2915 \mathrm{~cm}^{-1}$ in Figure 4(a) that shift to $2919 \mathrm{~cm}^{-1}$ in Figure 4(b), which indicates the presence of an alkene functional group (Ashraf et al. 2017; Abdić et al. 2018). The changes of band at $1603 \mathrm{~cm}^{-1}$ (Figure 4(a)) to $1606 \mathrm{~cm}^{-1}$ (Figure 4(b)) is corresponding to the asymmetric stretching of the carboxylic $\mathrm{C}=\mathrm{O}$ double bond, that is usually present in fibre materials containing pectin (Mahmoud et al. 2014). The peaks around $1245 \mathrm{~cm}^{-1}$ as seen in Figure 4(a) is due to C-O stretching vibrations in hemicellulose as well as $\mathrm{C}-\mathrm{O}$ stretching vibration of acetyl group $\mathrm{n}$ lignin. The absent of $1245 \mathrm{~cm}^{-1}$ peak noticed in Figure 4(b) after the adsorption process pointed to the loss of hemicellulose and lignin (Mohamed et al. 2017). The changes of bands observed from $675-652 \mathrm{~cm}^{-1}$ in Figure 4(a) to a single band of $667 \mathrm{~cm}^{-1}$, in Figure 4(b), may represents the aromatic C-H groups (Kim et al. 2020). The presence of functional groups (hydroxyl, carboxyl, amine, etc.) in BBP adsorbent had contribute to the adsorption processes of Mn.

\subsubsection{XRD Analysis}

264

XRD analysis of the BBP adsorbent before and after manganese adsorption is shown in Figure 5(a) and (b), respectively. Appearance of a broad low-intensity diffraction background and absence of sharp peaks, suggesting that the structure of BBP adsorbent is amorphous phase which related to the carbon structure (Bediako et al. 2019). Other than that, it is also due to organic materials and volatile substances. It was found that the presence of characteristic crystalline cellulose peaks manifested at $2 \theta \approx 22^{\circ}$. The peak is attributed to the characteristics crystal structure of cellulose (Mahmoodi et al. 2018). After adsorption, no significant differences were observed in the crystalline peaks of the BBP adsorbent as in Figure 5(b), except that the intensity of the phases declined which indicate that manganese ions were replacing the ions and altering the structure of the BBP adsorbent. This demonstrates that adsorption of manganese did not change the structure space of BBP adsorbents and therefore the adsorption process occurred on the surface.

\subsubsection{BET analysis} and surface chemistry of the adsorbent. The BET surface area for BBP adsorbent was $2.12 \mathrm{~m}^{2} / \mathrm{g}$ with the total pore volume of $0.0139 \mathrm{~cm}^{3} / \mathrm{g}$ and average pore diameter of $64.35 \mathrm{~nm}$. Nitrogen adsorption-desorption isotherms 

classification, the isotherm for BBP adsorbent is classified as type 2 which is macropores ( $>50 \mathrm{~nm})$. The pore size distribution makes it suitable for adsorbing manganese ions because it has an ionic radius about $0.80 \mathrm{~nm}$ (Goher et al. 2015). Therefore, manganese ions were able to enter the largest micropores (less than $2 \mathrm{~nm}$ according to IUPAC classification). The low surface area is a characteristic of most agro- or carbonaceous materials (Pathak and Kulkarni, 2017). However, the low surface area does not necessarily implying low adsorption potential of a material (Maia et al. 2021). The adsorption capacities of non-living biomasses are attributed mainly to the functional groups (amino, carbonyl, carboxyl) that present in the structure of the adsorbent (García-Mendieta and Solache-Ríos 2012).

289

\section{2. $\quad$ Batch Adsorption Studies}

\subsubsection{Effect of $\mathrm{pH}$}

292

Figure 7 displays the optimal performance of various $\mathrm{pH}$ conditions with a $0.1-0.7 \mathrm{~g}$ adsorbent dosage and initial manganese concentrations ranging from $10-50 \mathrm{mg} / \mathrm{L}$ in $60-180 \mathrm{~min}$ of contact time. The effect of $\mathrm{pH}$ ranges from 5-9 on the removal of Mn by the BBP adsorbent is shown in Figure 7(a). The surface charge on the BBP adsorbent can be used to explain the effect of $\mathrm{pH}$. It was observed that the removal of $\mathrm{Mn}$ achieved at maximum of $90 \%$ at $\mathrm{pH} 7$ as the initial $\mathrm{pH}$ was increased but gradually decreased over 7 . The adsorption increased when the $\mathrm{pH}$ of the solution increased because more negative-charged; metal-binding sites were exposed, attracting positive-charged metal ions and inducing adsorption onto the adsorbent surface (Mumtaz et al. 2014). The positive charge density of $\mathrm{H}^{+}$ion decreases with increasing $\mathrm{pH}$, which reduces electrostatic repulsion on the surface of BBP adsorbent and attracts more manganese ions, thus facilitating greater metal adsorption (Adekola et al. 2016). The lowest percentage removal of $\mathrm{Mn}^{2+}$ was found at $\mathrm{pH} 4$ and $\mathrm{pH}$ 5.5. This can be explained by the fact that the high $\mathrm{H}^{+}$ion concentration at low $\mathrm{pH}$ occupies most of the adsorbent's active sites, thus lowering manganese ion removal efficiency (Abdić et al. 2018). Saturation of the bonded active sites took place and became inaccessible to other cations (Fathi et al. 2020). According to Akl et al. (2013), pH solution strongly affects the surface charge on the solid particles. In addition, it also changes the properties and availability of metal ions in solution, as well as the chemical state of the functional groups during the adsorption process (Abdić et al. 2018). This could be attributed to the partial hydrolysis of $\mathrm{Mn}^{2+}$ ions with increasing $\mathrm{pH}$ that results in the formation of complexes $\mathrm{OH}^{-}$such as $\mathrm{Mn}(\mathrm{OH})^{+}, \mathrm{Mn}(\mathrm{OH})_{2}, \mathrm{Mn}_{2}(\mathrm{OH})_{3}{ }^{+}$and $\mathrm{Mn}_{2} \mathrm{OH}^{3+}$ species in solution. Therefore, the 
adsorption and precipitation of manganese-hydroxyl species into the adsorbent structure may be involved (Esfandiar et al. 2014). The dependency of Mn adsorption at higher $\mathrm{pH}$ is associated with the surface functional groups of the BBP adsorbent and the metal chemistry in the solution where the functional groups can be seen in the previous section in Figure 4. According to Feizi and Jalali (2015), dissociation of specific functional groups such as carboxyl and hydroxyl is important in metal sorption. As the $\mathrm{pH}$ increased, the functional groups would be exposed, increasing the density of negative charge on the surface of BBP adsorbent that contributes to the attraction between manganese ions and functional groups (Fathi et al. 2020). The adsorption capacity of BBP adsorbent is based on the $\mathrm{pH}$ value, together with surface charge and ionisation. Therefore, $\mathrm{pH} 7$ is the optimum $\mathrm{pH}$ value for maximum $\mathrm{Mn}$ removal in the present study

\subsubsection{Effect of Initial Manganese Concentration}

The effect of initial $\mathrm{Mn}$ ion concentration of $10-50 \mathrm{mg} / \mathrm{L}$ are depicted in Figure 7(b) where BBP adsorbent solution was employed with the optimal $\mathrm{pH} 8$ as shown in the previous section. It was perceived that the percentage of Mn removal decreases with the increase of initial Mn ions concentration. The initial of Mn concentration of $20 \mathrm{mg} / \mathrm{L}$ showed the total Mn removal of $100 \%$. A trend was observed in Figures 7(b)where Mn removal was decreased from $100 \%$ to $32 \%$, with increased initial $\mathrm{Mn}$ concentration from $10-50 \mathrm{mg} / \mathrm{L}$, respectively. This indicates that the surface saturation is dependent on the initial manganese concentration. The adsorbent surface area saturates at higher manganese concentration as the diffusion of the ions from the bulk solution to the adsorbent surface area decreases (Ali et al. 2017). Idrees et al. (2018) suggested that initial manganese ion concentration gives an impelling cause to overcome metal transfer resistances in the adsorbent and solution. This leads to a collision of higher probability between the active sites of BBP adsorbent and manganese ions. The adsorption sites become occupied at some point and reach a constant value where further adsorption from an aqueous solution is impossible. Adeogun et al. (2013) also showed that the removal of Mn ions using raw and oxalic acid modified rice husk adsorbent decreased with the increase in initial Mn concentration. Initially, adsorption occurs rapidly on the adsorbent's external surface, followed by a slower internal diffusion process, which may be the rate-determining step. This is comparable with this study, where the rate of adsorption is fast in the first 10 minutes, until almost equilibrium due to quick occupancy of Mn ions onto the surface of BBP adsorbent 
The effect of BBP dosage on the removal of manganese with the optimal initial Mn concentration of $20 \mathrm{mg} / \mathrm{L}$, at pH 7 is shown in Figure 7(c). The adsorbent dosage was employed from $0.1 \mathrm{~g} / \mathrm{L}$ to $0.7 \mathrm{~g} / \mathrm{L}$ and the experiments were shaken for 150 minutes. The obtained findings indicate that as the adsorbent dose is raised, the efficacy of Mn removal improves. The greatest Mn removal was $96 \%$ at the optimum adsorbent dosage of BBP $(0.5 \mathrm{~g} / \mathrm{L})$. High adsorbent dosage provides more active exchangeable adsorption sites. However, excessive adsorbent dosage could also decrease the adsorption rate due to interference caused by the interaction of active sites of the adsorbent (Iftekhar et al. 2018). Abdić et al.(2018) showed that the increase in the amount of tangerine peels adsorbent had increased the Mn removal efficiencies. This situation is because higher adsorbent dosage provides greater surface area and more metal-binding sites. Therefore, the rate of Mn adsorption was increased even when the initial metal concentration remained constant (Esfandiar et al. 2014). Furthermore, Mahmoud et al. (2014) also reported that increasing the banana peel activated carbon (BPAC) adsorbent dosage led to higher manganese adsorption. This can be attributed to the presence of more binding surfaces for manganese ions and the increased surface area (Ahmed et al, 2015). The effective surface area for adsorption was increased by increasing the adsorbent dosage (Adekola et al. 2014).

\subsubsection{Effect of Contact Time}

The time plays a vital role in the adsorption by BBP which was investigated within a time period of 30180 minutes in $250 \mathrm{~mL}$ of solution; $0.5 \mathrm{~g} / \mathrm{L}$ (BBP), initial $\mathrm{Mn}$ concentration of $20 \mathrm{mg} / \mathrm{L}$ and a $\mathrm{pH}$ of 7 . Determination of the optimal contact time is done after the optimum $\mathrm{pH}$ and initial concentration are determined (Kurniawati et al. 2021). Figure 7(d) shows that the optimum time of adsorption of Mn by BBP achieved 100\% of total removal when the contact time increased up to 150 minutes after equilibrium was achieved. Similar findings were reported by Hegazy et al. (2021) that removed 93\% of Mn within 120 minutes contact time until it reached equilibrium by using Moringa oleifera seeds adsorbent. and the second of which is the delayed release of adsorbent compounds. This is because the amount of adsorbed 
saturated the active site on the surface of the adsorbent, further adsorption time will no longer increase the adsorption and even tends to reduce it (Kurniawati et al. 2021).

\subsection{Comparison with previous studies on Mn removal under optimum conditions}

The result obtained under optimal Mn removal conditions for BBP in the previous experiments was performed to validate the optimal conditions. The validation experiment was conducted at $0.5 \mathrm{~g}$ of BBP adsorbent dose, initial Mn concentration of $20 \mathrm{mg} / \mathrm{L}$ at pH 7, and agitated for 150 minutes at $125 \mathrm{rpm}$. The results were close to the previous experiment with $98 \%$ Mn removal and clearly showed that the factors affecting the adsorption process for Mn removal was successfully determined. Table 1 shows BBP adsorbent has remarkable adsorption capacity as compared to other studies in the literature.

\subsection{Adsorption Isotherm Studies}

The adsorption relationships analysis using Langmuir and Freundlich isotherm for the adsorption of $\mathrm{Mn}$ are depicted in Figure 8. The experiment for both isotherms for Mn removal was analysed under optimised conditions as mentioned in the previous section. These two models have the simplest experimental activities of a wide range of operating conditions. According to the Langmuir isotherm, the uptake occurs on a homogeneous surface through monolayer sorption with no interaction between the adsorbed molecules (Mahmoud et al. 2014). Langmuir and Freundlich linear model were best fitted according to the predicted adsorption equilibrium as the correlation coefficients of $\mathrm{R}^{2}$ analysis; 0.984 (linear Langmuir) and 0.995 (linear Freundlich) compare to nonlinear Langmuir (0.388) and non-linear Freundlich (0.516), respectively.

Table 2 displayed the Langmuir and Freundlich constant isotherm on the established coefficient of $\mathrm{R}^{2}$ from the basis of the modelling curve. From the plot in Figure 8 (a) and (c), the correlation coefficients of $\mathrm{R}^{2}$ and the value calculated for $\mathrm{q}_{\max }$ is close to the experimental $\mathrm{q}_{\max }$, thus showing that the data fit to the linear Langmuir model. The $\mathrm{R}_{\mathrm{L}}$ value that is between 0 and $1\left(0<\mathrm{R}_{\mathrm{L}}<1\right)$, implied that the process is favourable (Adeogun et al. 2013). On the other hand, the determination correlation coefficients of $\mathrm{R}^{2}$ in linear Freundlich model was also in a good fit for the experimental data whereas the value of value of $1 / \mathrm{n}<1$ indicates that the process is favourable adsorption and the surface of adsorbent is highly heterogeneous (Adeogun et al. 2013).

The isotherm results obtained in the present study can be concluded that the experimental data for adsorption of Mn ions onto BBP adsorbent fitted to both linear isotherm model as the values for the correlation 
coefficients $\left(\mathrm{R}^{2}\right)$ were both high $\left(\mathrm{R}^{2}>0.98\right)$. The Mn adsorption behaviour on BBP adsorbent may occur in multilayers on the surface of the adsorbent. However, based on the satisfactory correlation coefficients, the data is also consistent with linear on both isotherm models in which the monolayer adsorption takes place on the BBP adsorbent.

\subsection{Adsorption Kinetics}

The graph of linear and non-linear of Pseudo-first order and second order kinetic is plotted in Figure 9, respectively. The regression coefficient must be high $\left(\mathrm{R}^{2}\right)$ and the calculated $\mathrm{q}_{\mathrm{e}}$ values should be closed to the experimental $\mathrm{q}_{\mathrm{e}}$ (Marque et al. 2013). These criteria must be satisfied in order to be fitted in these kinetic models. The kinetics adsorption of Mn onto the BBP adsorbent was well represented by the pseudo-second order whereas the linear and non-linear of Pseudo first order was unsuitable due to the low $\mathrm{R}^{2}$ values. The graph of Pseudo-first order in Figure 9 (a and c) shows poor correlation of parameters with $\mathrm{R}^{2}=0.840$ (linear) and $\mathrm{R}^{2}=0.875$ (nonlinear) while the graph for pseudo-second order was best described in Figure 9 (c) with high linear regression of $\mathrm{R}^{2}=0.99$

Table 2 represent the linear pseudo-second order is predominant kinetic model for the Mn adsorption by BBP adsorbent due to higher value of $\mathrm{R}^{2}$ than those in pseudo-first order. Furthermore, the pseudo-second order calculated $\mathrm{q}_{\mathrm{e}}$ values are in good agreement with the experimental $\mathrm{q}_{\mathrm{e}}$ values compared in the pseudo-first order model. Thus, this confirms that chemisorption of manganese onto the BBP adsorbent is the main mechanism in the adsorption process (Adekola et al. 2020; Zhang et al. 2014). In chemisorption, a chemical bond (usually covalent) is formed as metal ions adhere to adsorbent surface that also increase coordination number with the surface (Senthil et al. 2010). Based on the FTIR results (refer Section 3.1.3), hydroxyl and carboxyl were abundance and involved in chemical bonding. The possible ion exchange mechanisms is when $\mathrm{Mn}$ ion attached itself to two adjacent hydroxyl groups and two-oxyl groups which could donate two pairs of electrons to the metal ions, hence forming four coordination number compounds and releasing two hydrogen ions into solution (Omri and Benzina, 2019).

\subsection{Desorption studies}

Figure 10 shows the desorption of manganese by BBP adsorbent. The experiment was run at optimum condition obtain in adsorption study which is at 0.1M HCL acid, 0.5g BBP adsorbent, and 150 mins. Low concentration of HCL acid was used for effective desorption process as the reaction is more stable. In the first 
cycle, high desorption of manganese of $92 \%$ was attained in 30 minutes. The recovery of BBP adsorbent by using

427 HCL acid demonstrate high percentage of manganese desorbed in 5 minutes and reach maximum in 30 minutes.

428 However, the desorption efficiency was decreased to $51 \%$ in the second cycle and further decreased to $32 \%$ in the

429

430

431

432

433

434

435

436

437

438

439

440

441

442

443

444

445

446

447

448

449

450

451

452

453

454

third cycle. The loss rate after the third cycle desorption was $60 \%$. This might be due to the reduction of functional groups in BBP adsorbent surface and incomplete desorption during the regeneration process. Long-term elution can destroy the binding site or leave manganese ions in the adsorbent ( $\mathrm{Li}$ et al. 2021).

Figure 11 shows the recovery of BBP adsorbent for manganese removal. The recovery rate in the first cycle was $94.18 \%$ and decreased to $61.38 \%$ in the second cycle followed by $40.39 \%$ in the third cycle. This showed that the adsorption recovery was effective in the first cycle but was gradually decreased in the second and third cycle. These finding shows that BBP adsorbent has potential reusability and efficient for reused after the first cycle of desorption process. Increasing of desorption cycles lead to gradual destruction of the active binding sites on the adsorbent after each cycle. Therefore, the performance of the regenerated adsorbent is not comparable with the freshly prepared adsorbent. The decrease of desorption efficiency can also be caused by the saturation and occupation of adsorption sites with strongly adsorbed adsorbate (Vakili et al. 2019). Moreover, some chemical reagents could change the chemical structure of adsorbents by interacting with some constituents of the adsorbent (Omorogie et al. 2016). This will decrease adsorption capacity of the adsorbent as HCL acid could weaken some active sites in the adsorbent by leaching some ions into the desorbing solution with each desorbing cycle.

\section{Conclusion}

The chemical modified BBP adsorbent resulted in large surface area and crumpled shape of the adsorbent that cater for maximum adsorption rate. FTIR analysis reveals the presence of hydroxyl and carboxyl group that plays important role in adsorption process. XRD analysis suggests that the structure of BBP is amorphous while BET analysis indicate that the size distribution of BBP adsorbent is macropores. Isotherm studies show the experimental data was well presented by the linear Langmuir and Freundlich model. Additionally, the linear pseudo-second order provides a well linear regression with $\mathrm{R}^{2}$ of 0.99 . Hence, the mechanism for the adsorption of manganese by the BBP adsorbent is by chemisorption where the Mn ions adhere to the surface of BBP adsorbent by chemical bond. The efficiency of reusing BBP adsorbent for further adsorption process is after the first desorption cycle with the highest recovery rate of $94.18 \%$. According to the findings, BBP adsorbent is a potential natural adsorbent that is effective for treating water containing $\mathrm{Mn}$ at the optimum condition. Furthermore, the 
455 ability of the BBP adsorbent to be reused demonstrated that the adsorbent is economical and can reduce negative 456 impact to the environment.

\section{Acknowledgement} for providing the research facilities and equipment. The authors wish to thank the Ministry of Higher Education Malaysia for the Fundamental Research Grant Scheme grant (K219) (FRGS/1/2019/TK10/UTHM/03/3).

461 


\section{References}

Abdeen Z, Mohammad SG, Mahmoud MS (2015) Adsorption of Mn (II) ion on polyvinyl alcohol/chitosan dry blending from aqueous solution. Environmental Nanotechnology, Monitoring \& Management 3:1-9. https://doi.org/10.1016/j.enmm.2014.10.001

Abdić Š, Memić M, Šabanović E, Sulejmanović J, Begić S (2018) Adsorptive removal of eight heavy metals from aqueous solution by unmodified and modified agricultural waste: tangerine peel. International Journal of Environmental Science and Technology 5(12):2511-8. https://doi.org/10.1007/s13762-018-1645-7

Adekola FA, Hodonou DS, Adegoke HI (2016) Thermodynamic and kinetic studies of biosorption of iron and manganese from aqueous medium using rice husk ash. Applied Water Science 4:319-30. https://doi.org/10.1007/s13201-014-0227-1

Adeogun AI, Idowu MA, Ofudje AE, Kareem SO, Ahmed SA (2013) Comparative biosorption of Mn (II) and Pb (II) ions on raw and oxalic acid modified maize husk: kinetic, thermodynamic and isothermal studies. Applied Water Science 167-79. https://doi.org/10.1007/s13201-012-0070-1

Ahmadi S, Ganjidoust H (2021) Using banana peel waste to synthesize BPAC/ZnO nanocomposite for photocatalytic degradation of Acid Blue 25: Influential parameters, mineralization, biodegradability studies. Journal of Environmental Chemical Engineering 9(5):106010. https://doi.org/10.1016/j.jece.2021.106010

Ahmed F, Siwar C, Begum RA (2014) Water resources in Malaysia: Issues and challenges. J. Food Agric. Environ 12(2):1100-4.

Ahmed SA, El-Roudi AM, Salem AA (2015) Removal of Mn (II) from ground water by solid wastes of sugar industry. Journal of Environmental Science and Technology 8(6):338. https://doi.org/ $\underline{10.3923 / \text { jest.2015.338.351 }}$

Akl MA, Yousef AM, AbdElnasser S (2013) Removal of iron and manganese in water samples using activated carbon derived from local agro-residues. J. Chem. Eng. Process Technol 4(04). https://doi.org/10.4172/2157-7048.1000154

Ali A. Removal of Mn (II) from water using chemically modified banana peels as efficient adsorbent (2017) Environmental Nanotechnology, Monitoring \& Management 7:57-63. https://doi.org/10.1016/j.enmm.2016.12.004

Al-Jubouri SM, Holmes SM (2017) Hierarchically porous zeolite X composites for manganese ion-exchange and solidification: Equilibrium isotherms, kinetic and thermodynamic studies. Chemical Engineering Journal 308:476-91. https://doi.org/10.1016/j.cej.2016.09.081

Alvarez-Bastida C, Martínez-Miranda V, Solache-Ríos M, Linares-Hernández I, Teutli-Sequeira A, VázquezMejía G (2018) Drinking water characterization and removal of manganese. Removal of manganese from water. Journal of Environmental Chemical Engineering 6(2):2119-25. 
497

498

499

500

501

502

503

504

505

506

507

508

509

510

511

512

513

514

515

516

517

518

519

520

521

522

523

524

525

526

527

528

529

Ashraf A, Bibi I, Niazi NK, Ok YS, Murtaza G, Shahid M, Kunhikrishnan A, Li D, Mahmood T (2017) Chromium (VI) sorption efficiency of acid-activated banana peel over organo-montmorillonite in aqueous solutions. $\begin{array}{llll}\text { International journal of } & \text { 19(7):605-13. }\end{array}$ $\underline{\text { https://doi.org/10.1080/15226514.2016.1256372 }}$

Bangaraiah P (2018) Biosorption of manganese using tamarind fruit shell powder as a biosorbent. Research Journal of Pharmacy and Technology 11(10):4313-6. https://doi.org/10.5958/0974-360X.2018.00789.8.

Baysal A, Ozbek N, Akman S (2013) Determination of trace metals in waste water and their removal processes. Waste Water-Treatment Technologies and Recent Analytical Developments 145-71. http://dx.doi.org/10.5772/52025

Bediako JK, Sarkar AK, Lin S, Zhao Y, Song MH, Choi JW, Cho CW, Yun YS (2019) Characterization of the residual biochemical components of sequentially extracted banana peel biomasses and their environmental remediation applications. Waste management 141-53. $\underline{\text { https://doi.org/10.1016/j.wasman.2019.04.009 }}$

Bouchard MF, Surette C, Cormier P, Foucher D (2018) Low level exposure to manganese from drinking water and cognition in school-age children. Neurotoxicology 64:110-7. https://doi.org/10.1016/j.neuro.2017.07.024

Carolin CF, Kumar PS, Saravanan A, Joshiba GJ, Naushad M (2017) Efficient techniques for the removal of toxic heavy metals from aquatic environment: A review. Journal of environmental chemical engineering 5(3):2782-99. https://doi.org/10.1016/j.jece.2017.05.029

Chen L, Fang Y, Jin Y, Chen Q, Zhao Y, Xiao Y, Zhao H (2015) Biosorption of Cd2+ by untreated dried powder of duckweed Lemna aequinoctialis. Desalination and Water Treatment 53(1):183-94. https://doi.org/10.1080/19443994.2013.839399

Du X, Zhang K, Xie B, Zhao J, Cheng X, Kai L, Nie J, Wang Z, Li G, Liang H (2019) Peroxymonosulfate-assisted electro-oxidation/coagulation coupled with ceramic membrane for manganese and phosphorus removal in surface water. Chemical Engineering Journal365:334-43. https://doi.org/10.1016/j.cej.2019.02.028

Esfandiar N, Nasernejad B, Ebadi T (2014) Removal of Mn (II) from groundwater by sugarcane bagasse and activated carbon (a comparative study): application of response surface methodology (RSM). Journal of industrial and engineering chemistry. 20(5):3726-36. https://doi.org/10.1016/j.jiec.2013.12.072

Seyedpour, S. F., Rahimpour, A., Mohsenian, H., \& Taherzadeh, M. J. (2018). Low fouling ultrathin nanocomposite membranes for efficient removal of manganese. Journal of Membrane Science, 549, 205216. https://doi.org/10.1016/j.memsci.2017.12.012

Fathi A, Gahlan AA, Farghaly OA (2020) Decontamination of Copper and Manganese from Aqueous Media by Untreated and Chemically Treated Sugarcane Bagasse: A Comparative Study. Chemistry of Advanced 
Feizi M, Jalali M (2015) Removal of heavy metals from aqueous solutions using sunflower, potato, canola and walnut shell residues. Journal of the Taiwan Institute of Chemical Engineers 54:125-36. https://doi.org/10.1016/j.jtice.2015.03.027

534

535

536

537

538

539

540

541

542

543

544

545

546

547

548

549

550

551

552

553

554

555

556

557

558

559

560

561

562

563

García-Mendieta A, Olguín MT, Solache-Ríos M (2012) Biosorption properties of green tomato husk (Physalis philadelphica Lam) for iron, manganese and iron-manganese from aqueous systems. Desalination. 2012 Jan 4;284:167-74. https://doi.org/10.1016/j.desal.2011.08.052

Gerke TL, Little BJ, Maynard JB (2016) Manganese deposition in drinking water distribution systems. Science of the Total Environment 541:184-93. https://doi.org/10.1016/j.scitotenv.2015.09.054

Goher ME, Hassan AM, Abdel-Moniem IA, Fahmy AH, Abdo MH, El-sayed SM (2015) Removal of aluminum, iron and manganese ions from industrial wastes using granular activated carbon and Amberlite IR-120H. The Egyptian Journal of Aquatic Research. 2015 Jan 1;41(2):155-64. https://doi.org/10.1016/j.ejar.2015.04.002

Gopakumar A, Narayan R, Nagath SA, Nishanthan P (2018) Waste Water Treatment Using Economically Viable Natural Adsorbent Materials. Materials Today: Proceedings5(9):17699-703. https://doi.org/10.1016/j.matpr.2018.06.091।

Ihsanullah, Abbas, A., Al-Amer, A. M., Laoui, T., Al-Marri, M. J., Nasser, M. S., Khraisheh, M., \& Atieh, M. A. (2016). Heavy metal removal from aqueous solution by advanced carbon nanotubes: critical review of adsorption applications. Separation and Purification Technology, 157, 141-161. $\underline{\text { https://doi.org/10.1016/j.seppur.2015.11.039 }}$

Hegazy I, Ali ME, Zaghlool EH, Elsheikh R (2021) Heavy metals adsorption from contaminated water using Moringa seeds/olive pomace byproducts. Applied Water Science. 11(6):1-4. https://doi.org/10.1007/s13201-021-01421-5

Herawati D, Santoso SD, Amalina I (2018) Kondisi Optimum Adsorpsi-fluidisasi Zat Warna Limbah Tekstil Menggunakan Adsorben Jantung Pisang. Jurnal SainHealth 2(1):1-7. http://dx.doi.org/10.51804/jsh.v2i1.169.1-7

Idrees M, Batool S, Ullah H, Hussain Q, Al-Wabel MI, Ahmad M, Hussain A, Riaz M, Ok YS, Kong J (2018) Adsorption and thermodynamic mechanisms of manganese removal from aqueous media by biowastederived biochars. Journal of Molecular Liquids 266:373-80. https://doi.org/10.1016/j.molliq.2018.06.049

Iftekhar S, Ramasamy DL, Srivastava V, Asif MB, Sillanpää M (2018) Understanding the factors affecting the adsorption of Lanthanum using different adsorbents: a critical review. Chemosphere. 204:413-30. https://doi.org/10.1016/j.chemosphere.2018.04.053

Jawed A, Pandey LM (2019) Application of bimetallic Al-doped ZnO nano-assembly for heavy metal removal and decontamination of wastewater. Water Science and Technology 80(11):2067-78. 
Jeirani Z, Sadeghi A, Soltan J, Roshani B, Rindall B (2015) Effectiveness of advanced oxidation processes for the removal of manganese and organic compounds in membrane concentrate. Separation and Purification Technology 149:110-5. https://doi.org/10.1016/j.seppur.2015.05.009

Kim H, Ko RA, Lee S, Chon K (2020) Removal efficiencies of manganese and iron using pristine and phosphoric acid pre-treated biochars made from banana peels. Water. 12(4):1173. https://doi.org/10.3390/w12041173

Kurniawati D, Sari TK, Adella F, Sy S (2021) Effect of Contact Time Adsorption of Rhodamine B, Methyl Orange and Methylene Blue Colours on Langsat Shell with Batch Methods. InJournal of Physics: Conference Series 2021 Feb 1 (Vol. 1788, No. 1, p. 012008). IOP Publishing. https://doi.org/10.1088/1742$\underline{6596 / 1788 / 1 / 012008}$

Li X, Yu X, Liu L, Yang J, Liu S, Zhang T (2021) Preparation, characterization serpentine-loaded hydroxyapatite and its simultaneous removal performance for fluoride, iron and manganese. RSC Advances. 2021;11(27):16201-15. https://doi.org/10.1039/D1RA02028E

Mahmoodi NM, Taghizadeh M, Taghizadeh A (2018) Mesoporous activated carbons of low-cost agricultural biowastes with high adsorption capacity: preparation and artificial neural network modeling of dye removal from single and multicomponent (binary and ternary) systems. Journal of Molecular Liquids 269:217-28. https://doi.org/10.1016/j.molliq.2018.07.108

Mahmoud MS, Ahmed SM, Mohammad SG, Abou Elmagd AM (2014) Evaluation of Egyptian banana peel (Musa sp.) as a green sorbent for groundwater treatment. International Journal of Engineering and Technology (11):648-59.

Maia LS, Duizit LD, Pinhatio FR, Mulinari DR (2021) Valuation of banana peel waste for producing activated carbon via $\mathrm{NaOH}$ and pyrolysis for methylene blue removal. Carbon Letters 1-4. https://doi.org/10.1007/s42823-021-00226-5

Marques TL, Alves VN, Coelho LM, Coelho NM (2013) Assessment of the use of Moringa oleifera seeds for removal of manganese ions from aqueous systems. BioResources 8(2):2738-51.

Marsidi N, Hasan HA, Abdullah SR (2018) A review of biological aerated filters for iron and manganese ions removal in water treatment. Journal of Water Process Engineering 23:1-2. https://doi.org/10.1016/j.jwpe.2018.01.010

Meseldžija S, Petrović J, Onjia A, Volkov-Husović T, Nešić A, Vukelić N (2020) Removal of Fe2+, Zn2+ and $\mathrm{Mn} 2+$ ions from the mining wastewater by lemon peel waste. Journal of the Serbian Chemical Society. 2020;85(10):1371-82. https://doi.org/10.2298/JSC200413030M

Milatovic D and Gupta RC, (2018) “Manganese," in Veterinary Toxicology: Basic and Clinical Principles: Third Edition, Third Edit., Elsevier Inc., 445-454.

Mohamed RM, Hashim N, Abdullah S, Abdullah N, Mohamed A, Daud MA, Muzakkar KF (2020) Adsorption 
of Heavy Metals on Banana Peel Bioadsorbent. In Journal of Physics: Conference Series 2020 Jun 1 (Vol. 1532, No. 1, p. 012014). IOP Publishing. https://doi.org/10.1088/1742-6596-1532-1-012014

Mthombeni NH, Mbakop1and S, Onyango MS. Adsorptive removal of manganese from industrial and mining wastewater (2016) InProceedings of Sustainable Research and Innovation Conference pp. 36-45.

Mumtaz MW, Mukhtar H, Anwar F, Saari N (2014) RSM Based Optimization of Chemical and Enzymatic Transesterification of Palm Oil : Biodiesel Production andAssessment of Exhaust Emission Levels, Sci. World J., 1-11.

Omorogie MO, Babalola JO, Unuabonah EI (2016) Regeneration strategies for spent solid matrices used in adsorption of organic pollutants from surface water: a critical review. Desalination and water treatment. 57(2):518-44. https://doi.org/10.1080/19443994.2014.967726

Omri A, Benzina M (2012) Removal of manganese (II) ions from aqueous solutions by adsorption on activated carbon derived a new precursor: Ziziphus spina-christi seeds. Alexandria Engineering Journal51(4):34350. https://doi.org/10.1016/j.aej.2012.06.003

Pathak PD, Mandavgane SA, Kulkarni BD (2017) Fruit peel waste: characterization and its potential uses. Current Science 444-54.

Rumsby P, Rockett L, Clegg H, Jonsson J, Benson V, Harman M, Doyle T, Rushton L, Wilkinson D, Warwick P (2014) Speciation of manganese in drinking water. Toxicology Letters (229):S120. https://doi.org/10.1016/j.toxlet.2014.06.431

Kumar, P. S., Vincent, C., Kirthika, K., \& Kumar, K. S. (2010). Kinetics and equilibrium studies of Pb2+ in removal from aqueous solutions by use of nano-silversol-coated activated carbon. Brazilian Journal of Chemical Engineering, 27(2), 339-346. https://doi.org/10.1590/S0104-66322010000200012

Singh NB, Nagpal G, Agrawal S (2018) Water purification by using adsorbents: a review. Environmental technology \& innovation 11:187-240. https://doi.org/10.1016/j.eti.2018.05.006

Surovka D, Pertile E (2017) Sorption of Iron, Manganese, and Copper from Aqueous Solution Using Orange Peel: Optimization, Isothermic, Kinetic, and Thermodynamic Studies. Polish Journal of Environmental Studies 26(2). https://doi.org/10.15244/pjoes/60499

Tobiason, J.E., Bazilio, A., Goodwill, J., Mai, X., and Nguyen, C. (2016) Manganese Removal from Drinking Water Sources. Current Pollution Reports, 2, 168-177. Current Pollution Reports. https://doi.org/10.1007/s40726-016-0036-2

Vakili M, Deng S, Cagnetta G, Wang W, Meng P, Liu D, Yu G (2019) Regeneration of chitosan-based adsorbents used in heavy metal adsorption: A review. Separation and Purification Technology 224:373-87. https://doi.org/10.1016/j.seppur.2019.05.040

Zhang Y, Zhao J, Jiang Z, Shan D, Lu Y (2014) Biosorption of Fe (II) and Mn (II) ions from aqueous solution by rice husk ash. Biomed research international. 2014. https://doi.org/10.1155/2014/973095 

application of nanoscale zero-valent iron and its composites for the removal of heavy metal ions: a review. Environmental science \& technology 50(14):7290-304. https://doi.org/10.1021/acs.est.6b01897 
637 Table 1 Comparison of the present study findings with previous studies.

638 Table 2 Langmuir and Freundlich isotherm equilibrium parameters for manganese adsorption onto BBP adsorbent

640 Table 1 Comparison of the present study findings with previous studies.

\begin{tabular}{|c|c|c|c|c|c|c|}
\hline Adsorbent & $\begin{array}{c}\text { Manganese } \\
\text { removal } \\
(\%)\end{array}$ & pH & $\begin{array}{l}\text { Contact } \\
\text { time }(\min )\end{array}$ & $\begin{array}{l}\text { Adsorbent } \\
\text { dosage (g) }\end{array}$ & $\begin{array}{l}\text { Mn conc. } \\
(\mathrm{mg} / \mathrm{L})\end{array}$ & References \\
\hline Moringa seed & 93 & 5 & 120 & 5 & 50 & $\begin{array}{c}\text { (Hegazy et al. } \\
\text { 2021) }\end{array}$ \\
\hline Olive pomace & 91 & 5 & 120 & 5 & 50 & $\begin{array}{c}\text { (Hegazy et al. } \\
\text { 2021) }\end{array}$ \\
\hline $\begin{array}{l}\text { Biochar-banana } \\
\text { peel }\end{array}$ & 46 & 7 & 180 & 3 & 10 & (Kim et al. 2020) \\
\hline Lemon peel & 78.2 & 4 & 15 & 1 & 25 & $\begin{array}{c}\text { (Meseldzija et al. } \\
\text { 2020) }\end{array}$ \\
\hline Beet pulp & 86.4 & 6 & 90 & 1 & 2 & $\begin{array}{c}\text { (Ahmed et al. } \\
\text { 2015) }\end{array}$ \\
\hline $\begin{array}{l}\text { Tamarind fruit } \\
\text { shell }\end{array}$ & 74 & 3 & 60 & 1.2 & 100 & $\begin{array}{c}\text { (Bangaraiah, } \\
\text { 2018) }\end{array}$ \\
\hline $\begin{array}{l}\text { Sugarcane } \\
\text { Bagasse }\end{array}$ & 62.5 & 6 & 150 & 0.15 & 2 & $\begin{array}{c}\text { (Ahmed et al. } \\
\text { 2015) }\end{array}$ \\
\hline BBP & 98 & 7 & 150 & 0.5 & 20 & This study \\
\hline
\end{tabular}

641

642 Table 2 Langmuir and Freundlich isotherm equilibrium parameters for manganese adsorption onto BBP 643 adsorbent

\begin{tabular}{cccc}
\hline \multirow{2}{*}{ Model } & Parameters & Non-linear & Linear \\
\hline Langmuir & $\mathrm{q}_{\max }$ & 15 & 15.089 \\
\cline { 2 - 4 } & $\mathrm{R}_{\mathrm{L}}$ & 2.14 & 0.02 \\
\cline { 2 - 4 } & $\mathrm{R}^{2}$ & 0.388 & 0.984 \\
\cline { 2 - 4 } & $1 / \mathrm{n}$ & 0.2365 & 0.25 \\
\cline { 2 - 4 } & $\mathrm{kf}$ & 8 & 2.294 \\
\cline { 2 - 4 } & $\mathrm{R}^{2}$ & 0.516 & 0.995 \\
\cline { 2 - 4 } & $\mathrm{qe}$ & 14.15 & 62.783 \\
\cline { 2 - 4 } & $\mathrm{K}_{1}$ & 1.81 & 2.04 \\
\cline { 2 - 4 } & $\mathrm{R}^{2}$ & 0.875 & 0.840 \\
\hline Pseudo-first order & $\mathrm{qe}^{2}$ & 14.33 & 0.881 \\
\cline { 2 - 4 } & $\mathrm{K}_{1}$ & 1.671 & 0.991 \\
\hline
\end{tabular}


645 Figure 1 Schematic of BBP adsorbent preparation via chemical treatment

646 Figure 2 Scanning Electron Microscopic of pristine BBP adsorbent before adsorption of Mn with EDX analysis

647 Figure 3 Scanning Electron microscopic of pristine BBP adsorbent before adsorption of Mn with EDX analysis

648 Figure 4 FTIR analysis of BBP adsorbent (a) before and (b) after manganese adsorption

649 Figure 5 XRD pattern of BBP adsorbent (a) before and (b) after manganese adsorption

650 Figure 6 Nitrogen adsorption-desorption isotherms and pore size distribution curves (inset) of BBP adsorbent

651 Figure 7 Effect of (a) $\mathrm{pH}$, (b) initial Mn concentration (mg/L), (c) BBP adsorbent dosage (g/L) and (d) contact 652 time (minutes) for Mn removal

653 Figure 8 (a) Linear and (b) non-linear of Langmuir isotherm; (c) Linear and (d) non-linear of Freundlich 654 isotherm model for Mn adsorption using BBP

655 Figure 9 (a) Linear and (b) non-linear of Pseudo first order; (c) Linear and (d) non-linear of Pseudo second order kinetic model for Mn adsorption using BBP

657 Figure 10 Desorption of manganese by BBP adsorben

658 Figure 11 Recovery of BBP adsorbent for manganese removal

659

660
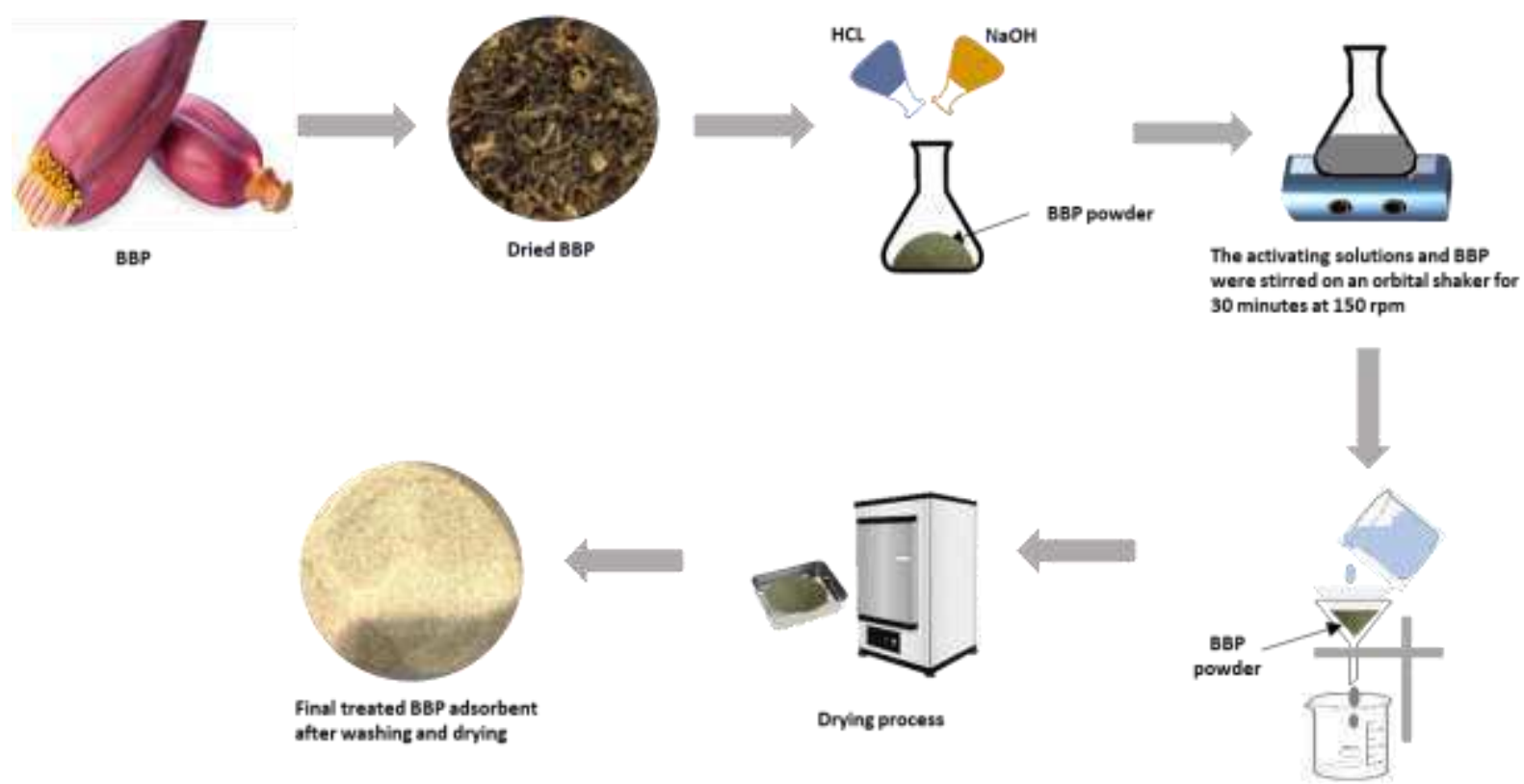

Treated BBP powder were rinsed with distilled water 

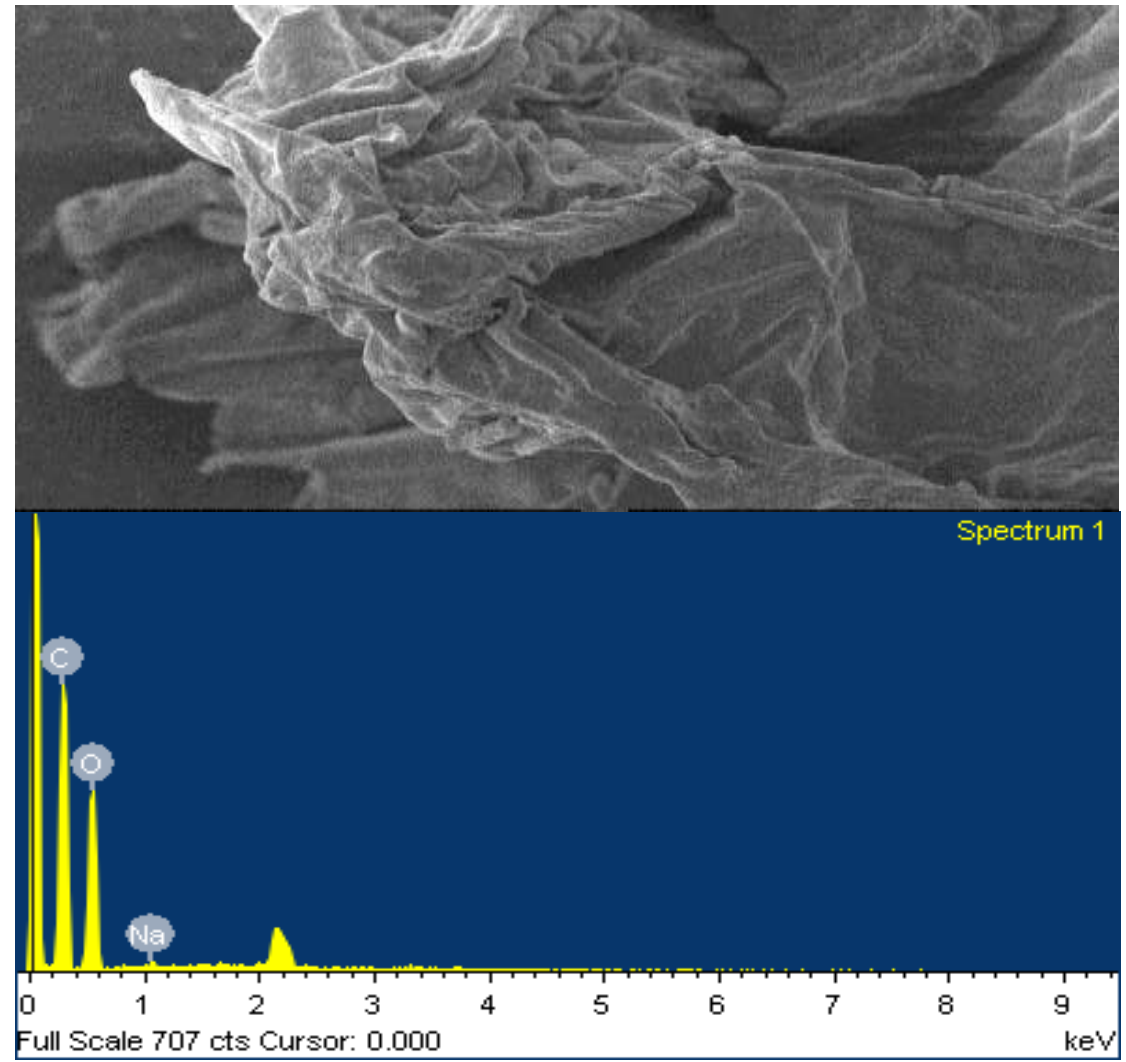

665 Figure 2 Scanning Electron Microscopic of pristine BBP adsorbent before adsorption of Mn with EDX analysis 666

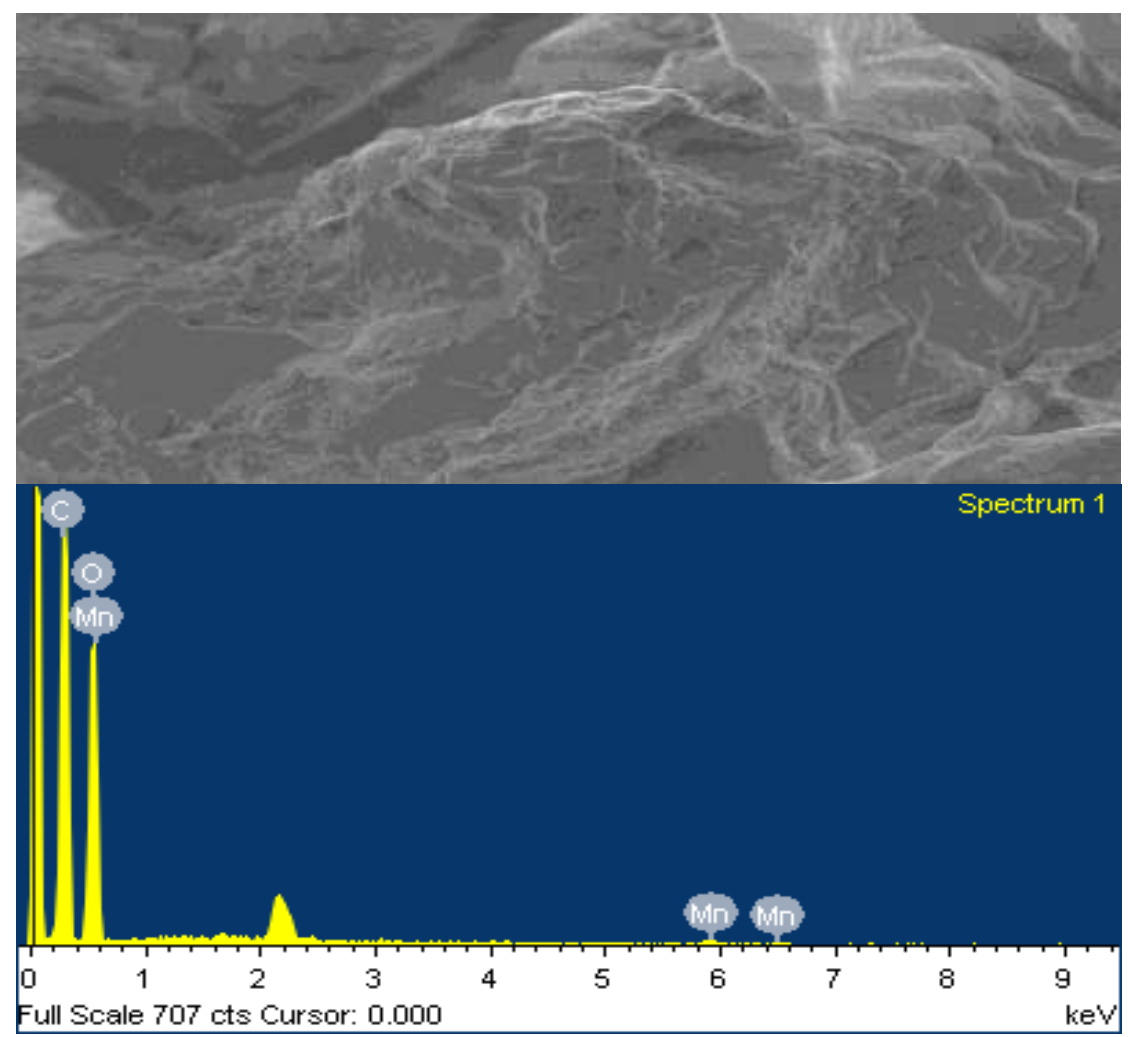



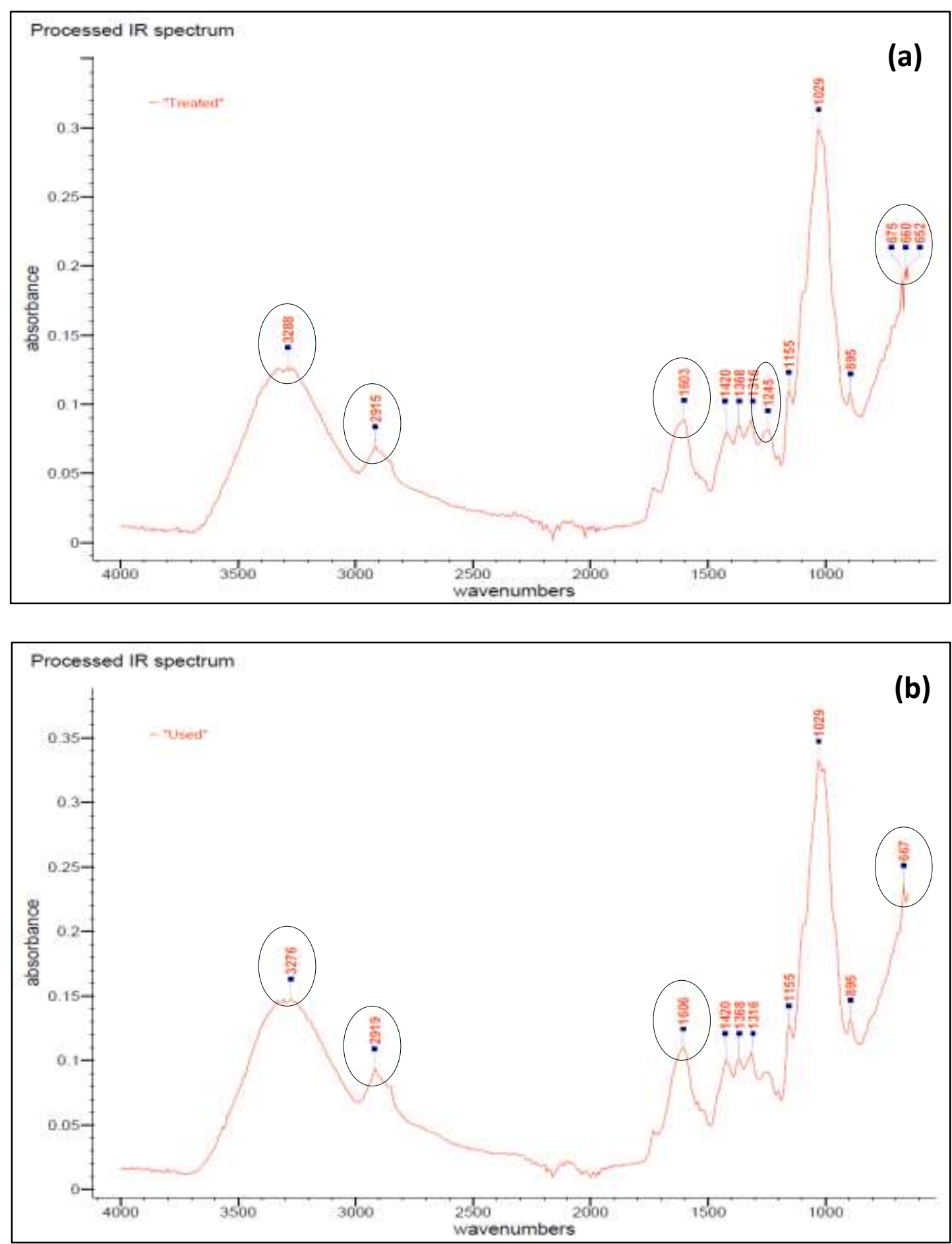

Figure 4 FTIR analysis of BBP adsorbent (a) before and (b) after manganese adsorption 


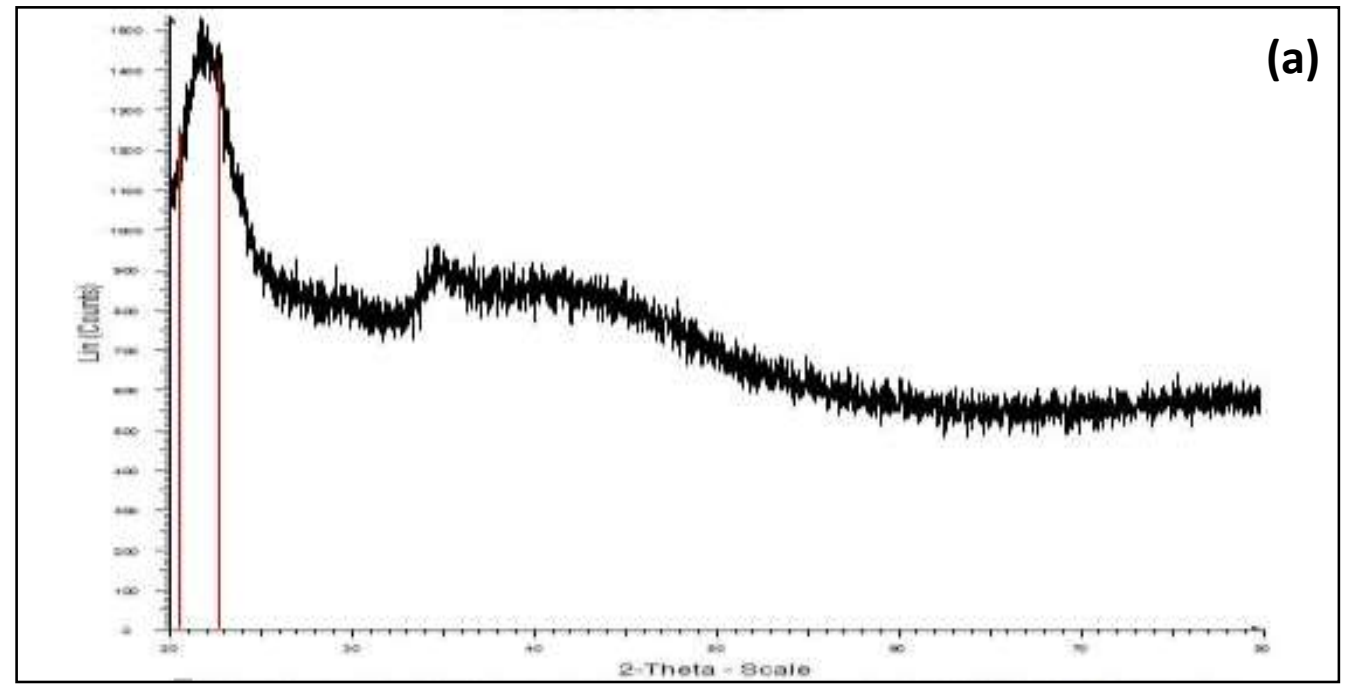

672

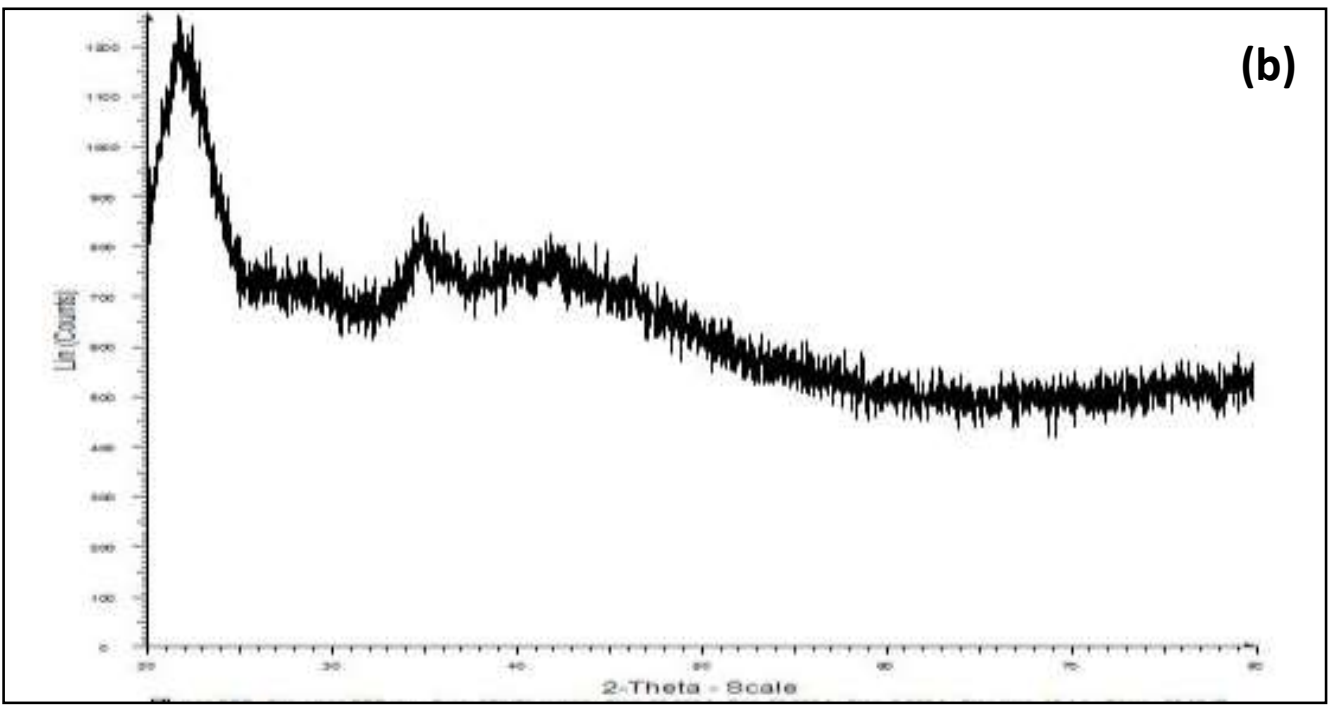

Figure 5 XRD pattern of BBP adsorbent (a) before and (b) after manganese adsorption 


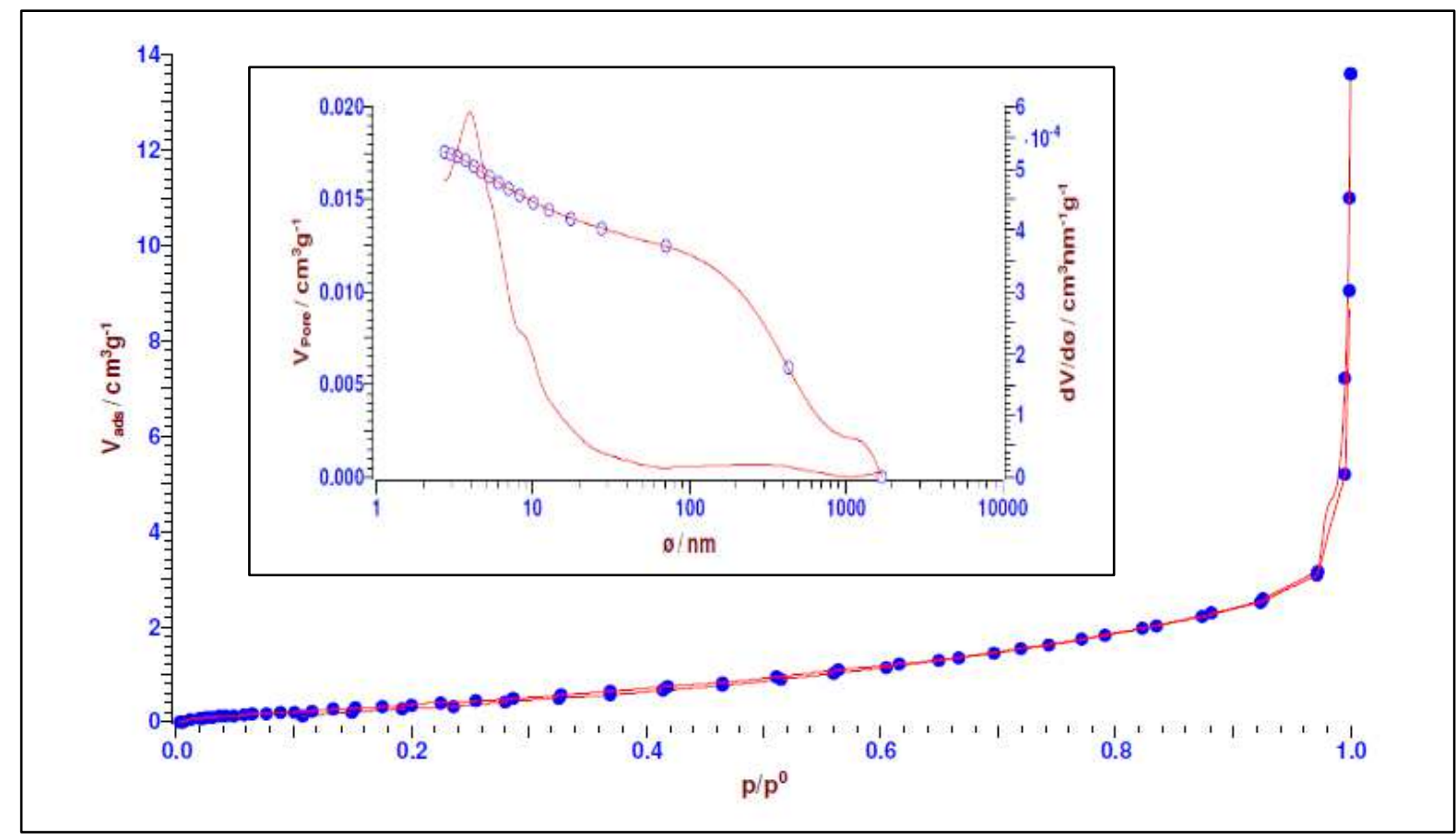

Figure 6 Nitrogen adsorption-desorption isotherms and pore size distribution curves (inset) of BBP adsorbent
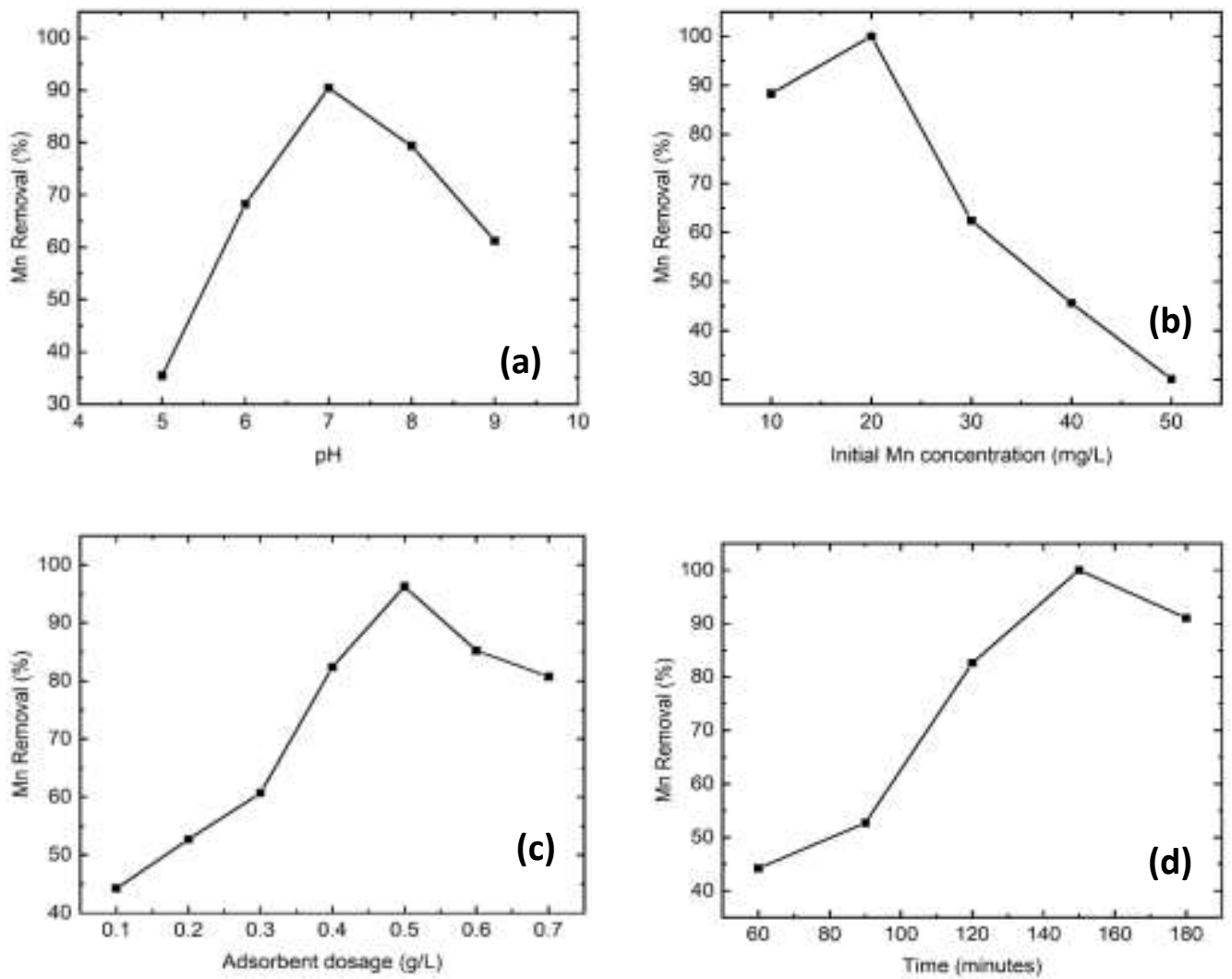

Figure 7 Effect of (a) pH, (b) initial Mn concentration (mg/L), (c) BBP adsorbent dosage (g/L) and (d) contact time (minutes) for Mn removall 

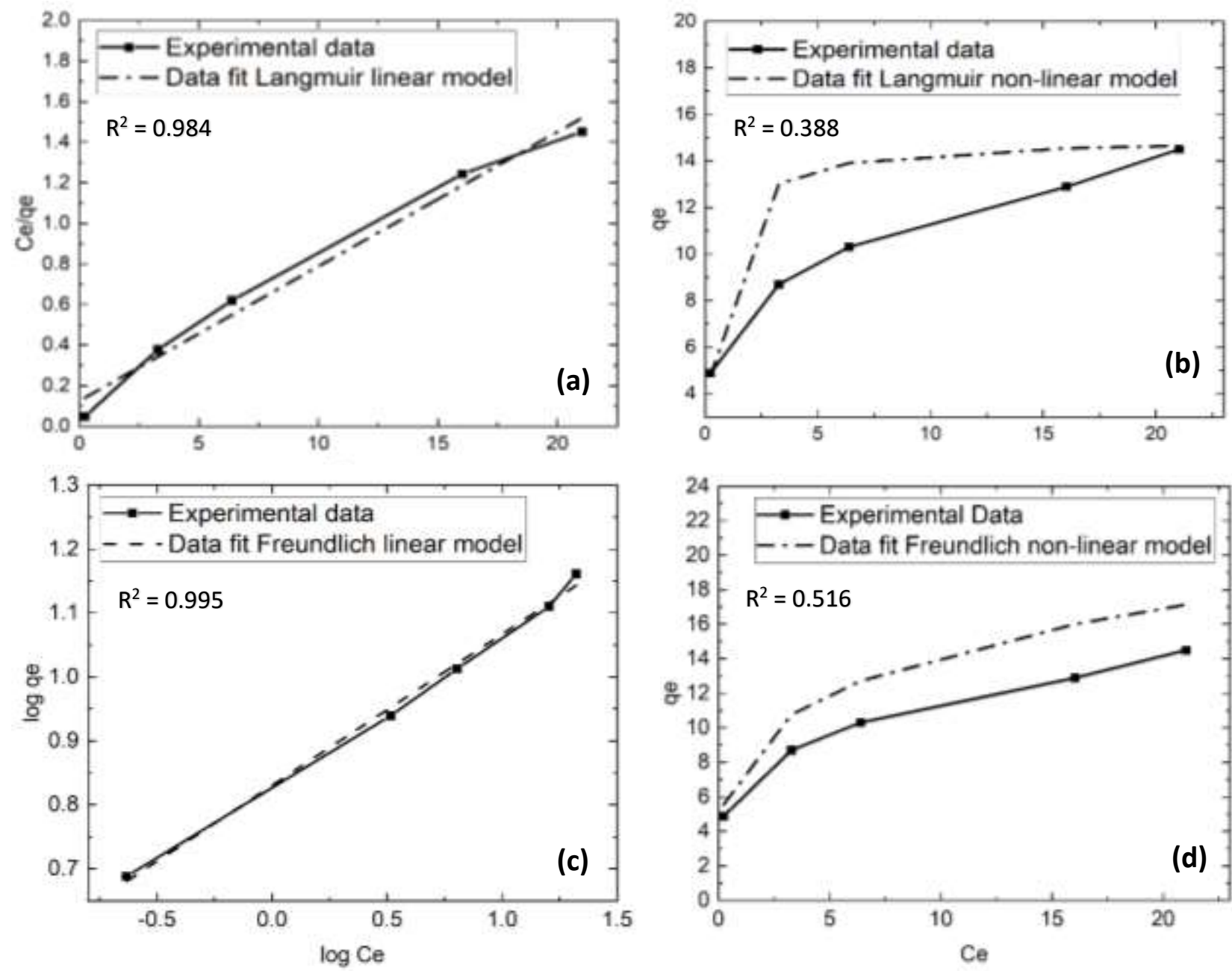

by6

Figure 8 (a) Linear and (b) non-linear of Langmuir isotherm; (c) Linear and (d) non-linear of Freundlich isotherm model for Mn adsorption using BBP 

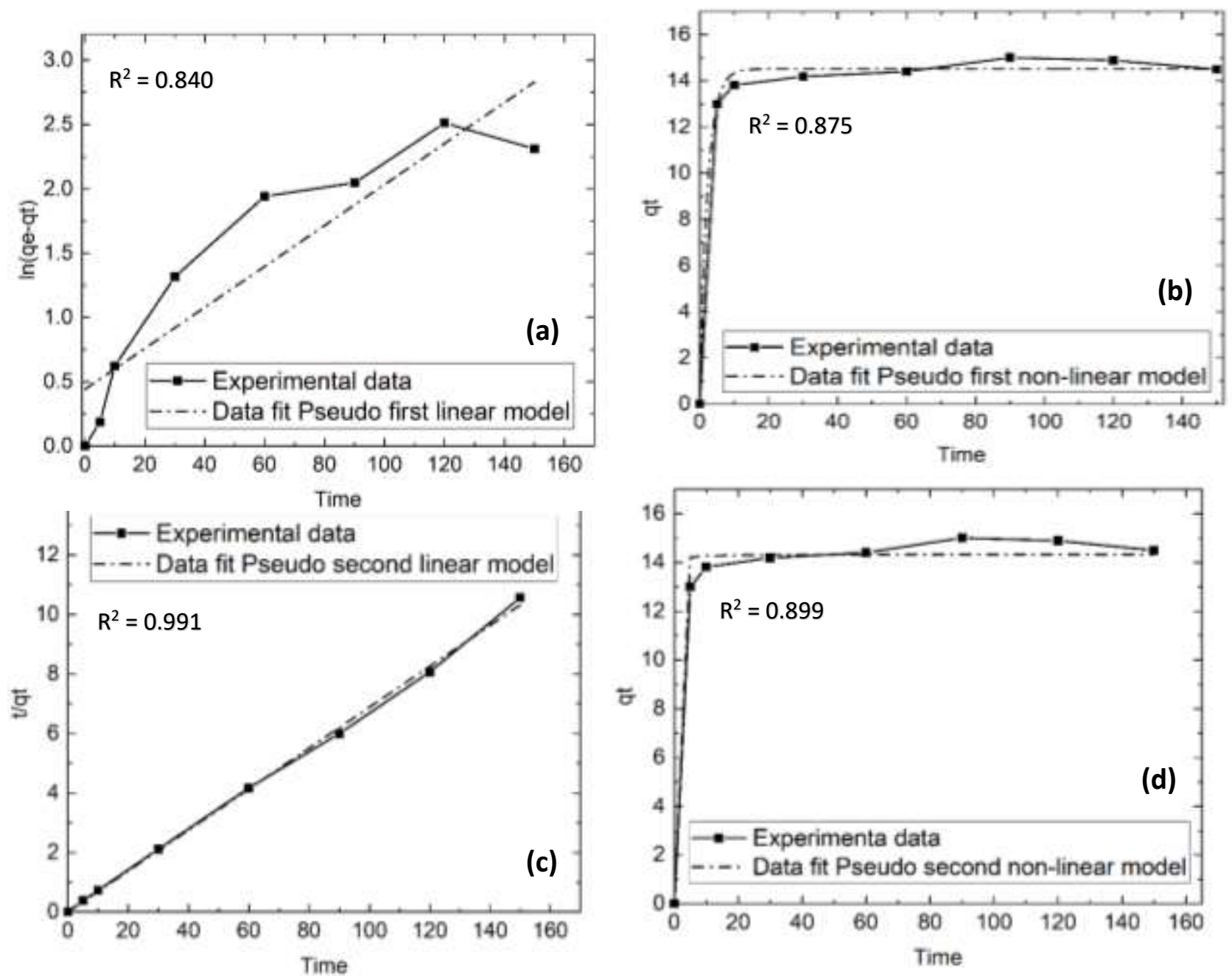

Figure 9 (a) Linear and (b) non-linear of Pseudo first order; (c) Linear and (d) non-linear of Pseudo second order kinetic model for Mn adsorption using BBP 


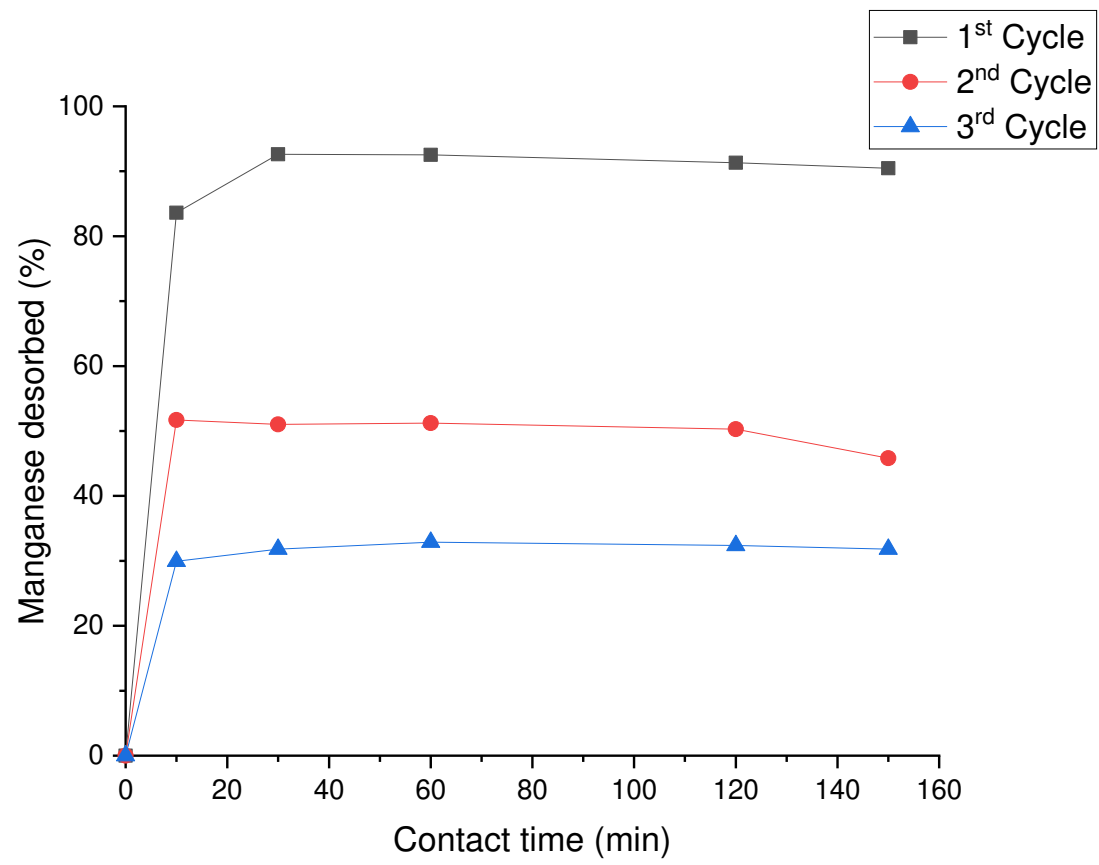

722

723

724

Figure 10 Desorption of manganese by BBP adsorbent

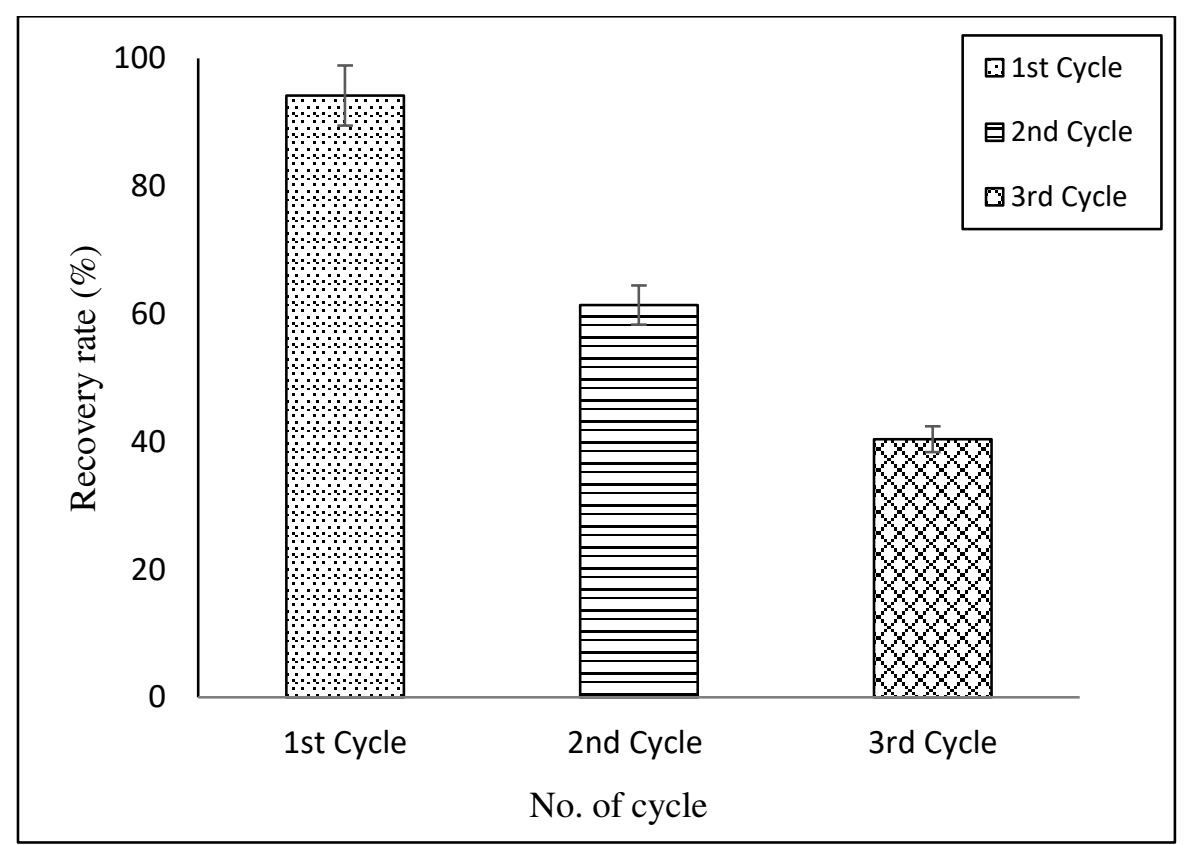

Figure 11 Recovery of BBP adsorbent for manganese removal 